\title{
Determination of capsaicinoids and carotenoids for the characterization and geographical origin authentication of paprika by UHPLC-APCI- HRMS
}

Ane Arrizabalaga-Larrañaga ${ }^{\mathrm{a}, \# \text {, Guillem Campmajón }}{ }^{\mathrm{a}, \mathrm{b}, \# \text {, Javier Saurina }}{ }^{\mathrm{a}, \mathrm{b}}$, Oscar Núñez ${ }^{\mathrm{a}, \mathrm{b}, \mathrm{c}}$, Francisco Javier Santos ${ }^{\mathrm{a}}$, Encarnación Moyano ${ }^{\mathrm{a}, *}$

a Department of Chemical Engineering and Analytical Chemistry, University of Barcelona, Barcelona, Spain

$\mathrm{b}$ Research Institute in Food Nutrition and Food Safety, University of Barcelona, Santa Coloma de Gramenet, Spain

c Serra Húnter Program, Generalitat de Catalunya, Barcelona, Spain

* Corresponding author: Encarnación Moyano Morcillo

Department of Chemical Engineering and Analytical Chemistry

University of Barcelona

Av. Diagonal 645, E-08028, Barcelona, Spain

Tel.: +34-93-403-9277

E-mail: encarna.moyano@ub.edu

ORCID: $\quad$ Ane Arrizabalaga-Larrañaga (0000-0002-9379-5775)

Guillem Campmajó (0000-0002-9252-0032)

Javier Saurina $\quad$ (0000-0002-4892-9535)

Oscar Núñez (0000-0001-5850-8972)

Francisco Javier Santos (0000-0002-8959-0363)

Encarnación Moyano (0000-0002-1233-8864)

\# These authors contributed equally in the research of this work. 


\section{Abstract}

2

3

4

5

6

7

8

9

The production area mislabeling of a food product is considered a fraudulent practice worldwide. In this work, a method that uses ultra-high-performance liquid chromatography coupled to high-resolution mass spectrometry using atmospheric pressure chemical ionization (UHPLC-APCI-HRMS) was used for the geographical origin authentication of paprika based on the determination of capsaicinoids and carotenoids. Satisfactory instrumental method performance was obtained, providing good linearity $\left(\mathrm{R}^{2}>0.998\right)$, run-to-run and day-to-day precisions (\%RSD $<15$ and $10 \%$, respectively), and trueness (relative errors $<10 \%$ ), while method limits of quantification were between 0.21 and $51 \mathrm{mg} \cdot \mathrm{kg}^{-1}$. Capsaicinoids and carotenoids were determined in 136 paprika samples, from different origins (La Vera, Murcia, Hungary, and the Czech Republic) and types (hot, sweet, and bittersweet). The composition of capsaicinoids and carotenoids was used as chemical descriptors to achieve paprika authentication through a classification decision tree built by partial least squares regression-discriminant analysis (PLS-DA) models and reaching a rate of $80.9 \%$.

7 Keywords: Paprika; Capsaicinoids; Carotenoids; UHPLC-HRMS; Food authentication. 


\section{Introduction}

Food authentication has become a concern for consumers, manufacturers, researchers, and international government administrations, due to the recent increase of food fraud, which implies illegal manipulation practices of foodstuff (e.g., adulteration, ingredient substitution, mislabeling, and dilution) with an economic gain purpose. It aims to certify intrinsic food properties, usually related to quality and safety, geographical origin, and production systems (Medina, Perestrelo, Silva, Pereira, \& Câmara, 2019). Among food products, spices are at extremely high risk of food fraud ("Food Fraud Risk Information,” 2020; Hong et al., 2017) because of their high cost and demand, as well as their complex supply chain. Other vulnerabilities, such as availability of the crops or weather events, also influence (Galvin-King, Haughey, \& Elliott, 2018).

Paprika is a dried and ground spice obtained from different varieties of red pepper (genus Capsicum that belongs to the Solanaceae family). Its distinctive organoleptic properties, such as intense red color, characteristic aroma, and sometimes, a pungent flavor, make it widely used in international cuisines, although it is also employed in the cosmetic and pharmaceutical fields. Some of these properties are mainly related to bioactive substances named capsaicinoids and carotenoids. Moreover, these compounds have been found to gather human health beneficial aspects, being both anticarcinogenic substances, among others (de Sá Mendes \& Branco de Andrade Gonçalves, 2020).

The worldwide production of paprika was estimated to be around four million tons in 2018, with Asia being the main producer ("Food and Agriculture Organization of the United Nations,” 2019). Its production in Europe is mainly located in Spain and certain countries in Eastern Europe such as Hungary and the Czech Republic. Moreover, the European Commission on Agriculture and Rural Development distinguishes six European paprika products with the Protected Designation of Origin (PDO) ("European 
47 Commission. eAmbrosia - the EU geographical indications register,” 2020)]: Pimentón de La Vera (Spain), Pimentón de Murcia (Spain), Kalocsai füszerpaprika-örlemény (Hungary), Szegedi füszerpaprika-örlemény (Hungary), Piment d'Espelette (France), and Paprika Žitava (Slovakia). The presence of the PDO label ensures the geographical origin as well as the inherent qualities of the product. However, it is also related to higher prices, making them more vulnerable to fraudulent practices such as the mislabeling of the agricultural origin of paprika. Therefore, analytical methodologies to detect and prevent these frauds are needed.

In the last years, a large variety of analytical strategies combined with chemometrics —mostly using principal component analysis (PCA), linear discriminant analysis (LDA), and partial least squares regression-discriminant analysis (PLS-DA) - have been developed to address the authenticity of paprika origin. For instance, some authors have proposed multi-elemental content profiling, determined by both inductively coupled plasma optical emission spectroscopy (IPC-OES) or mass spectrometry (ICP-MS), for the authentication of Szegedi füszerpaprika PDO (Brunner, Katona, Stefánka, \& Prohaska, 2010), the comparison of hot and sweet Hungarian paprika (Ördög et al., 2018), and the discrimination between La Vera and Murcia denominations (Ana PalaciosMorillo, Jurado, Alcázar, \& De Pablos, 2014). Instead, other techniques such as spectrophotometric measurements(A. Palacios-Morillo, Jurado, Alcázar, \& Pablos, 2016) or the combination of different parameters (e.g., sample moisture, elemental analysis, and total ash, lipids, nitrogen, saccharides content)(Václav Štursa , Pavel Diviš, 2018) have also been evaluated. Alternatively, several chromatographic fingerprinting approaches using high-performance liquid chromatography with electrochemical detection (HPLC/ECD)(Serrano et al., 2018) or ultraviolet detection (HPLC/UV) (Cetó, Sánchez, Serrano, Díaz-Cruz, \& Núñez, 2020; Cetó et al., 2018), and ultra-high-performance liquid 
chromatography coupled to high-resolution mass spectrometry (UHPLC-HRMS)

(Barbosa, Saurina, Puignou, \& Núñez, 2020), have recently focused on La Vera and Murcia PDO discrimination and adulteration detection.

Chemical profiling based on the determination of targeted compounds by liquid chromatography-mass spectrometry (LC-MS) has also been exploited to authenticate paprika according to its agricultural origin. The presence, distribution, and content of bioactive substances is directly related to many food features, such as the production area. Thus, they are commonly used as chemical descriptors for classificatory purposes through a semi-quantification (Campmajó, Núñez, \& Núñez, 2019). To date, ultra-highperformance liquid chromatography coupled to tandem mass spectrometry (UHPLCMS/MS) for targeted polyphenols and UHPLC-HRMS for polyphenols and capsaicinoids (Barbosa, Saurina, Puignou, \& Nuñez, 2020), and polyphenols and carbohydrates (Mudrić et al., 2017), have also been evaluated for paprika classification. Thereby, although capsaicinoid and carotenoid content has been extensively studied in red pepper and its derived products (Giuffrida et al., 2013; Nagy, Daood, Koncsek, Molnár, \& Helyes, 2017), their simultaneous analysis has not yet been used to deal with the classification of paprika. Therefore, this study aimed to develop an UHPLC-HRMS method for the determination of capsaicinoids and carotenoids in European paprika, and the subsequent use of target compound composition for the geographical origin authentication by multivariate chemometric methodologies.

\section{Experimental}

\subsection{Reagents and materials}

Chemical formula, acronyms, and chemical structures of target capsaicinoids and carotenoids are summarized in Fig. 1 and they were purchased from Sigma-Aldrich

96 (Steinheim, Germany) with purities higher than 90\%. 
Individual stock standard solutions of capsaicinoids $\left(1,000 \mathrm{mg} \cdot \mathrm{L}^{-1}\right)$ were prepared in LC-MS grade methanol, except capsaicin and dihydrocapsaicin that were prepared in ethanol, while carotenoid were prepared in acetonitrile $\left(500 \mathrm{mg} \cdot \mathrm{L}^{-1}\right)$. Intermediate mixture containing all target compounds $\left(50 \mathrm{mg} \cdot \mathrm{L}^{-1}\right)$ was weekly prepared from stock solutions by appropriate dilution in acetonitrile:acetone $(1: 1, v: v)$ and was subsequently used to obtain calibration solutions $\left(0.001\right.$ to $\left.10 \mathrm{mg} \cdot \mathrm{L}^{-1}\right)$ for quantification. All stock solutions were stored at $-20^{\circ} \mathrm{C}$ until their use.

Acetone for pesticide residue analysis ( $\geq 99.8 \%$ ), LC-MS grade water, methanol, and acetonitrile were purchased from Sigma-Aldrich, whereas absolute ethanol for analysis was obtained from Panreac (Barcelona, Spain). Moreover, a $0.22 \mu \mathrm{m}$ pore size Nylon membrane (Whatman, Clifton, NJ, USA) was employed to filter mobile phase components before their use.

\subsection{Instrumentation}

An UHPLC system equipped with an Accela 1250 quaternary pump, an Accela autosampler, and a column oven (Thermo Fisher Scientific, San Jose, CA, USA) was used for the chromatographic separation. Accucore $C_{18}$ analytical column $(100 \mathrm{~mm} \times 2.1 \mathrm{~mm}$ id., $2.6 \mu \mathrm{m}$ particle size) and guard column (10 mm × $2.1 \mathrm{~mm}$ id., $2.6 \mu \mathrm{m}$ particle size), both packed with superficially porous particles, were employed for the chromatographic separation of both carotenoid and capsaicinoid families. The developed chromatographic method used a quaternary gradient elution program with water, methanol, acetonitrile, and acetone as solvent $\mathrm{A}, \mathrm{B}, \mathrm{C}$, and $\mathrm{D}$, respectively. After optimization of the chromatographic separation (see Section 3.2) the gradient elution program used in this study started with a 3 min isocratic step at $60 \%$ solvent A and $40 \%$ solvent $C$ and followed by a linear gradient elution up to $80 \%$ solvent $\mathrm{C}$ in $0.5 \mathrm{~min}$, and an isocratic step at these last conditions for 2.5 min. Later, solvent B was introduced, and the mobile 
122 phase was linearly changed to $10 \%$ solvent B and $90 \%$ solvent C in 1.25 min, keeping in 123 these conditions for 3 min. Afterward, another linear gradient elution changed the composition in 1 min up to 50\% solvent $\mathrm{C}$ and $\mathrm{D}$ and kept at isocratic conditions for 1.5 min. Finally, solvent D was linearly increased up to $80 \%$ in 3 min, and this last percentage was used in an isocratic step for 2 min, before turning back to the initial conditions. The mobile phase flow rate was $600 \mu \mathrm{L} \cdot \mathrm{min}^{-1}$, the injection volume was $10 \mu \mathrm{L}$, and the column oven temperature was $25^{\circ} \mathrm{C}$.

The UHPLC system was coupled to a hybrid quadrupole-Orbitrap mass spectrometer chemical ionization (APCI) source (positive-ion mode). Nitrogen was purchased from Linde (Barcelona, Spain) and used as a sheath, sweep, and auxiliary gas at flow rates of 60, 0 , and 40 a.u. (arbitrary units), respectively. Both vaporizer and capillary temperatures were set at $350{ }^{\circ} \mathrm{C}$, corona discharge current at $+6 \mathrm{kV}$ and SLens $\mathrm{RF}$ level at $70 \mathrm{~V}$. The Q-Exactive Orbitrap system was tuned and calibrated every three days, using a calibration solution for positive-ion mode. The HRMS instrument operated in full scan MS mode ( $\mathrm{m} / \mathrm{z} 50-700)$ at a mass resolution of 70,000 full width at half maximum (FWHM) at $\mathrm{m} / \mathrm{z}$ 200. Moreover, an automatic gain control of $3.0 \times 10^{-6}$ and a maximum injection time of 200 ms was used. For the analysis of samples, two-events acquisition mode was used: an MS full scan and an "all-ion fragmentation” (AIF) (m/z 50 - 700, in both events) with stepped normalized collision energies (NCE) of 20, 30, $40 \mathrm{eV}$ for ion fragmentation. The Xcalibur software $v 4.1$ (Thermo Fisher Scientific) was used to control the LC-MS system and to acquire and process data.

\subsection{Sample analysis}

A total of 136 paprika samples from different origins and types were purchased 
147 and the Czech Republic; regarding types, hot, bittersweet, and sweet paprika were considered. Table 1 summarizes sample details such as the acronyms used for each region and the number of samples analyzed for each type of sample.

A simple solid-liquid extraction of target analytes from paprika samples was carried out as follows: $0.05 \mathrm{~g}$ of paprika were extracted with $4 \mathrm{~mL}$ of methanol:acetone $(1: 1, \mathrm{v} / \mathrm{v})$ solution in a $15 \mathrm{~mL}$ PTFE tube. Subsequently, the sample was stirred in a Stuart Vortex for 0.5 min (Staffordshire, United Kingdom) and sonicated for 10 min (5510 Branson ultrasonic bath, Hampton, NH, USA). Afterward, the extract was centrifuged for 15 min at 4,500 rpm (ROTANTA 460 HR Centrifuge, Hettich, Germany). Finally, the supernatant was filtered through $0.22 \mu \mathrm{m}$ Nylon membrane filters and stored at $4{ }^{\circ} \mathrm{C}$ in 2 at low and medium level concentrations, being near and around ten times higher than the

\subsection{Instrumental and quality parameters}

Instrumental and method limits of detection (ILODs, MLODs) were estimated as the smallest analyte concentration, providing a well-defined chromatographic peak with a good peak shape. This criterion was used because of the absence of baseline noise in the extracted ion chromatograms using a narrow mass tolerance window $(<5 \mathrm{ppm})$ under high-resolution mass spectrometry conditions (FWHM 70,000 at $\mathrm{m} / \mathrm{z}$ 200) on the Orbitrap mass analyzer. Instead, instrumental and method limits of quantification (ILOQs, MLOQs) were calculated from LOD values and considering the established ratio of three to ten between LODs and LOQs. In this way, ILODs have been determined using standard solutions in solvent injected directly into the UHPLC-HRMS system, whereas MLODs were calculated considering the sample treatment recovery and the matrix effect. Besides, both precision and trueness were studied by analyzing in triplicate two standard solutions LOQs, respectively. Precision (run-to-run and day-to-day) was expressed as the relative 
172 standard deviation (RSD, \%), whereas trueness was defined as the relative error (RE, \%),

173 both calculated according to the obtained concentrations.

Due to the lack of a blank paprika (free of target analytes), matrix effect (ME, \%) in the UHPLC-APCI-HRMS method was evaluated by spiking a sweet paprika from the Czech Republic (which presented the lowest concentration of target compounds) at 1 $\mathrm{mg} \cdot \mathrm{kg}^{-1}$. This concentration was three times higher than the endogenous one determined previously in the same sample. Thus, the ME in the ionization process was evaluated by estimating the relative difference between the chromatographic peak area obtained in the analysis of the spiked extract and that obtained from the analysis of standard mixtures at the same concentration level. matrix, which is mathematically decomposed into the submatrices of scores $\mathrm{T}$

194 (coordinates of the samples) and loadings PT (eigenvectors), providing information on 195 
potential outlier samples bases on the distance to the center of the model calculated from the Hoteling $\mathrm{T}^{2}$ and $\mathrm{Q}$ statistical parameters, being $\mathrm{T}^{2}$ the sum of the normalized squared scores and Q the sum of squares of residuals of a given sample.

In this study, PLS-DA has been used as the classification method. The PLS-DA model is built from a training set composed of well-known paprika samples belonging to the different classes to be assessed. At this stage, PLS-DA assigns each sample into a class (numerically encoded depending on the origin and type), following rules based on the distance to the center of each class, calculated from $\mathrm{T}^{2}$ and $\mathrm{Q}$. The classification model is established to reach the minimum prediction error in assigning these calibration samples into their actual classes.

More details of the theoretical background of these chemometric techniques are addressed elsewhere (Massart, D. L., Vandeginste, B. G. M., Buydens, L. M. C., de Jong, S., Lewi, P.J., \& Smeyers-Verbeke, 1997).

PCA and PLS-DA X-data matrices consisted of the target compounds' concentration levels as a function of the paprika samples under study, while PLS-DA Y-data matrices defined the membership of each sample in a class. Before building the chemometric model, data was autoscaled to provide the same weight to each variable by suppressing differences in their magnitude and amplitude scales. Moreover, the most suitable number of latent variables (LVs) in PLS-DA was established at the first significant minimum point of the cross-validation (CV) error. Venetian blinds were set by default as the CV method, except for small data matrices (less than twenty paprika samples), where the leave-one-out method were employed. Moreover, considering the complexity of the studied issue, where several sample origins and types were presented, the classification has not been obtained from the segregation of all the classes at once but sequentially using HMB. Therefore, different PLS-DA models were consecutively combined, breaking 
221 down the classification aim into sub-groups. The applicability of the built chemometric

method was evaluated through external validation: $70 \%$ of a sample group was used as the training set (data set used for model generation and optimization), and the remaining $30 \%$ as the test set.

A quality control (QC) sample, consisting of a mix prepared with $50 \mu \mathrm{L}$ of each paprika sample extract, was used to control the repeatability and robustness of the chemometric results as well as to detect systematic errors. In this line, samples were also randomly injected to minimize the influence of instrumental drifts in the models.

\section{Results and discussion}

3.1. HRMS and AIF (HRMS) characterization of targeted capsaicinoids and carotenoids

In the present work, four capsaicinoids (nordihydrocapsaicin, NDC; capsaicin, CAP; dihydrocapsaicin, DC; nordihydrocapsiate, NDCT) and six carotenoids (capsanthin, CT; capsorubin, CR; violaxanthin, VIO; lutein, LUT; $\beta$-cryptoxanthin, $\beta_{-}$ CRYPT; $\beta$-carotene, $ß-C A R)$ were determined by UHPLC-APCI-HRMS in paprika samples. These compounds are commonly found in red pepper-derived products (Arimboor, Natarajan, Menon, Chandrasekhar, \& Moorkoth, 2015; Schweiggert, Carle, \& Schieber, 2006) and their structures are depicted in Fig. 1.

The ions generated by APCI for targeted compounds were studied using a hybrid high-resolution mass spectrometer (quadrupole-Orbitrap) equipped with a high-energy collision dissociation (HCD) cell. This instrument allows monitoring ions at HRMS and fragmenting them to provide more specific chemical structural information useful for confirmatory purposes. Thus, the mass spectral information of ions generated in APCI (positive-ion mode) are summarized in Table 2. The mass spectra of CAP, DC, and NDC 
showed the protonated molecule $[\mathrm{M}+\mathrm{H}]^{+}$as base peak, and they did not show any adduct ion. Nevertheless, an intense signal at $m / z 137.0597$ (Rel Ab. 20-70\%) always appeared due to the in-source CID fragmentation of the protonated molecule because of the $\beta$ cleavage at the N-R bond. (Reilly et al., 2003). In addition, ions at $m / z 170.1536$ (CAP), $m / z$ 172.1693 (DC), and m/z 158.1537 (NDC), were assigned to a common loss (136.0518 Da) from the protonated molecule $\left[\mathrm{M}+\mathrm{H}-\mathrm{C}_{8} \mathrm{H}_{8} \mathrm{O}_{2}\right]^{+}$, which corresponded to the fraction of the acyl chain that results from removing the aromatic ring (Schweiggert et al., 2006). Instead, the mass spectrum of NDCT showed the in-source collision-induced dissociation (CID) fragment ion at $m / z 137.0597$ as base peak because, after the above mentioned $\beta$ cleavage, the charge remained in the common fragment $\left[\mathrm{C}_{8} \mathrm{H}_{9} \mathrm{O}_{2}\right]^{+}$. Nevertheless, although most of the carotenoids also showed the $[\mathrm{M}+\mathrm{H}]^{+}$as the base peak, a significant in-source CID fragmentation where a water molecule is lost $\left[\mathrm{M}+\mathrm{H}-\mathrm{H}_{2} \mathrm{O}\right]^{+}$was observed in some cases (CR, m/z 583.4137; VIO, m/z 583.4137; CT, m/z 567.4186; ß-CRYPT, m/z 535.4291; LUT, $m / z$ 551.4239). Moreover, this in-source CID fragment ion was the base peak of LUT and CR, as displayed in other studies (Arrizabalaga-Larrañaga, Rodríguez, Medina, Santos, \& Moyano, 2020).

The UHPLC-APCI-HRMS method was carried out using independent data analysis based on two scanning events - HRMS full scan and all ion fragmentation (AIF) - to improve detectability and obtain structural information of target analytes. Regardless of the compound fragmentation, to obtain a rich AIF mass spectrum within the whole $\mathrm{m} / \mathrm{z}$ range studied, the full scan of fragment ions was performed by employing stepped normalized collision energies (NCE: 20, 30, $40 \mathrm{eV}$ ). In this way, it provided the average of AIF (HRMS) mass spectra at the different collision energies. Fig. 2 shows the HRMS spectrum and AIF (HRMS) spectrum of (A) DC and (B) CT. 
The AIF (HRMS) spectrum was obtained for all targeted compounds and the diagnostic fragment ions, the corresponding ion assignments, and the accurate mass errors are summarized in Table 2. Each family of compounds showed a distinctive fragmentation pathway. For instance, all capsaicinoids showed common fragment ions $\mathrm{m} / \mathrm{z}$ 137.0597, $\mathrm{m} / \mathrm{z}$ 122.0362, $\mathrm{m} / \mathrm{z} 94.0413$ and $\mathrm{m} / \mathrm{z} 66.0464$ (Fig. 2). The fragment ion at $\mathrm{m} / \mathrm{z} 122.0362$

$274\left[\mathrm{C}_{7} \mathrm{H}_{6} \mathrm{O}_{2}\right]^{+}$was produced by the $\alpha$-cleavage of the $\mathrm{C}-\mathrm{O}$ bond, generating the dissociation 275 of the methylene moiety from the fragment ion at $\mathrm{m} / \mathrm{z} 137.0597\left[\mathrm{C}_{8} \mathrm{H}_{9} \mathrm{O}_{2}\right]^{+}(\mathrm{Wolf}$, 276 Huschka, Raith, Wohlrab, \& Neubert, 1999). Moreover, the ion at $\mathrm{m} / \mathrm{z} 122.0362$ $\left[\mathrm{C}_{7} \mathrm{H}_{6} \mathrm{O}_{2}\right]^{+\bullet}$ can be further fragmented through neutral losses of $\mathrm{CO}(27.9943 \mathrm{Da})$ to form both fragment ions at $\mathrm{m} / \mathrm{z} 94.0413\left[\mathrm{C}_{7} \mathrm{H}_{6} \mathrm{O}_{2}-\mathrm{CO}\right]^{+\bullet}$ and $\mathrm{m} / \mathrm{z} 66.0464\left[\mathrm{C}_{7} \mathrm{H}_{6} \mathrm{O}_{2}-\mathrm{C}_{2} \mathrm{O}_{2}\right]^{+\bullet}$. These fragmentation steps may involve the opening of the aromatic ring, yielding into these linear polyunsaturated chain ions. On the other hand, carotenoids presented other characteristic common fragment ions such as $\left[\mathrm{C}_{11} \mathrm{H}_{13}\right]^{+}\left(\mathrm{m} / \mathrm{z}\right.$ 145.1012), $\left[\mathrm{C}_{9} \mathrm{H}_{11}\right]^{+}(\mathrm{m} / \mathrm{z}$ 119.0855), and $\left[\mathrm{C}_{8} \mathrm{H}_{9}\right]^{+}(\mathrm{m} / \mathrm{z}$ 105.0699), which were generated because of the fragmentation of the high polyene conjugation. In addition, CR and VIO isomers showed the same fragment ion $\left[\mathrm{C}_{15} \mathrm{H}_{21} \mathrm{O}_{2}\right]^{+}(\mathrm{m} / \mathrm{z} 221.1536)$ corresponding to the oxo-cycle fused to the 3-hydroxy- $\beta$-ring and produced by the cleavage between carbons 10 and 11 (Wolf et al., 1999). Moreover, the fragment ion $\left[\mathrm{C}_{8} \mathrm{H}_{13}\right]^{+}(\mathrm{m} / \mathrm{z}$ 109.1011) presented in both AIF (HRMS) spectrum of CR and CT (Fig. 2) corresponded to the dehydrated five-membered ring (Breemen, Dong, \& Pajkovic, 2012).

\subsection{UHPLC-HRMS method development}

The chromatographic separation of all target compounds was performed in a reversed-phase UHPLC Accucore $\mathrm{C}_{18}$ column, under a quaternary gradient elution with water, methanol, acetonitrile, and acetone as the mobile phase components. The gradient elution was based on a chromatographic method previously developed for the separation 
of chlorophylls and carotenoids (Arrizabalaga-Larrañaga, Rodríguez, Medina, Santos, \&

295 Moyano, 2019). However, some modifications were required to deal with the simultaneous determination of capsaicinoids and carotenoids. Hence, given the differences in polarity among both families of compounds, the water content of the mobile phase at the beginning of the gradient elution was increased to ensure an effective separation of the most polar capsaicinoids (Daood et al., 2015). Thus, an isocratic step of water:acetonitrile $(60: 40, v / v)$ was included as starting elution conditions followed by a linear gradient up to 20:80 to retain capsaicinoids and allow their elution after four-fold the hold-up time $\left(t_{\mathrm{M}}\right)$, which corresponded to $0.97 \mathrm{~min}$, and before carotenoids. The inclusion of CR and CT among the carotenoid compounds made necessary to lengthen the isocratic step of methanol:acetonitrile $(10: 90, v / v)$. Moreover, the mobile phase eluotropic strength had to be increased at the end of the chromatographic run using acetonitrile:acetone $(50: 50, v / v)$ to allow the elution of $\beta$-CAR, the most hydrophobic carotenoid. Under the final gradient elution (see section 2.2.), a baseline separation of all target compounds was achieved in less than 15 minutes, except for CAP and NDC, which partially co-eluted. However, the isotope cluster of their ions did not overlap; thus, they could be isolated in individual extracted chromatograms according to $\mathrm{m} / \mathrm{z}$. Besides, the study of ion suppression or ion enhancement for these co-eluting compounds was carried out by injecting individual standard solutions and a mixture of the co-eluting target compounds $\left(1 \mathrm{mg} \cdot \mathrm{L}^{-1}\right)$ in the UHPLC-APCI-HRMS. The difference of the obtained did not affect their responses. 
319 the concentration range, $0.001-10 \mathrm{mg} \cdot \mathrm{kg}^{-1}$ for most of the compounds and $0.1-10 \mathrm{mg} \cdot \mathrm{kg}^{-}$

$320{ }^{1}$ for $ß-$ CRYPT and LUT, was satisfactory and showed correlation coefficients $\left(\mathrm{R}^{2}\right)$

321 higher than 0.998 . ILODs ranged from 0.001 to $0.025 \mathrm{mg} \cdot \mathrm{kg}^{-1}$ for most of the target

322 compounds, although for ß-CRYPT and LUT values were slightly higher (0.1 and 0.25

$323 \mathrm{mg} \cdot \mathrm{kg}^{-1}$, respectively). In terms of RSD and based on concentration values, run-to-run

324 and day-to-day precision were always lower than $15 \%$ and $10 \%$, respectively. Moreover,

325 the trueness, based on the same concentration values, showed relative errors below $10 \%$.

326 These results demonstrated the good instrumental performance of the developed

327 UHPLC-APCI-HRMS method for the determination of capsaicinoids and carotenoids.

328 Besides, before the determination of capsaicinoids and carotenoids by UHPLC-APCI-

329 HRMS in paprika, samples were submitted to a solid-liquid extraction. Because of the

330 differences in the physicochemical properties of both families of compounds, three

331 commonly used solvents, methanol, acetonitrile, and acetone, as well as mixtures of them,

332 were evaluated to achieve the most effective simultaneous extraction of target

333 compounds. It was found that acetonitrile had less effectiveness in extracting carotenoids

334 than both pure acetone and the mixture methanol:acetone. Moreover, pure methanol

335 extracted more efficiently capsaicinoids, than pure acetonitrile or acetone. Nevertheless,

336 the combination of both methanol and acetone seemed to improve the solubility of these

337 compounds, and thus, as a compromise, a mixture methanol:acetone $(1: 1, v / v)$ was chosen

338 as the most effective solvent for the simultaneous extraction of both capsaicinoids and

339 carotenoids (section 2.3.) in agreement with Nagy et al. who proposed a similar solvent

340 mixture (Nagy et al., 2017). Using the proposed extraction procedure, estimated MLODs

341 ranged from 0.06 to $1.5 \mathrm{mg} \cdot \mathrm{kg}^{-1}$ for most of the analytes, except for $\beta-C R Y P T$ and LUT,

342 which were 6.1 and $15.3 \mathrm{mg} \cdot \mathrm{kg}^{-1}$, respectively. While, MLOQs were comprised between

$343 \quad 0.21$ and $51 \mathrm{mg} \cdot \mathrm{kg}^{-1}$. 


\subsection{Analysis of paprika samples}

In this work, to test the potential of the UHPLC-APCI-HRMS method to determine capsaicinoids and carotenoids for authentication purposes, a total of 136 paprika samples from different regions were analyzed. Samples from countries such as Spain (La Vera and Murcia), Hungary, and the Czech Republic, as well as distinct flavor types (hot, sweet, and bittersweet), were evaluated.

Matrix-effect in the ionization of target compounds was evaluated as described in section 2.4 and the results showed ME\% values from 10 to 50\%. These results indicated that analytical correction strategies for accurate quantitative results should be performed. In this line, matrix-matched calibration cannot be applied to the determination of endogenous bioactive compounds because of the lack of blank samples. Instead, although standard addition calibration and isotope dilution mass spectrometry (IDMS) allow the correction of the matrix effect, they are not suitable for this study since standard addition calibration is time-consuming for the analysis of large sample batches, and IDMS requires expensive internal labeled standards, which are not available for all the target compounds. Therefore, these drawbacks make it difficult to apply these strategies to obtain an accurate quantitative analysis of capsaicinoids and carotenoids in paprika samples. Instead, some published studies have proposed to extract the targeted compounds from the food matrix to obtain blank samples that are proposed to be used in matrix-matched calibration. However, this strategy completely modifies the original food matrix, and thus, its application was not considered in this study. Therefore, external calibration methods are commonly proposed in most of the published studies dealing with the determination of these families of compounds in food and natural samples. For instance, capsaicinoids and carotenoids in paprika have been determined by some authors using only one or two available standards because of the chemical structural similarities (Barbero, Liazid, 
Ferreiro-González, Palma, \& Barroso, 2016; Bijttebier et al., 2014; Stipcovich, Barbero,

370 Ferreiro-González, Palma, \& Barroso, 2018). Moreover, since the present study aimed to

371

372 determine capsaicinoids and carotenoids for their use as chemical descriptors for paprika authentication, and the matrix influence could contribute as a potential source of discrimination between samples, external standard calibration method by employing ten standards was performed for the analysis of paprika samples. Thereby, the results obtained for the presence of both capsaicinoids and carotenoids in the 136 paprika samples analyzed are summarized in Table S1 (Supporting Material).

The qualitative capsaicinoid and carotenoid patterns (UHPLC-APCI-HRMS chromatograms) observed for all paprika samples were similar in terms of compounds detected, but they showed differences in the corresponding abundances. As an example, the diversity of the capsaicinoid and carotenoid profile is shown in Fig. 3, depicting the extracted UHPLC-APCI-HRMS chromatograms obtained from the analysis of a sweet paprika sample from (A) Murcia “MS9” and (B) Hungary “HS5”. To better study the relationship between their concentration and the type and production country of the samples, the total capsaicinoid and carotenoid contents, as well as the capsaicinoid/carotenoid ratio were evaluated. (Table S2 and Fig. S1).

For instance, independently of the geographical origin, hot paprika showed a higher total capsaicinoid content, $656 \pm 453 \mathrm{mg} \cdot \mathrm{kg}^{-1}$, and hence a higher capsaicinoid ratio (4090\%), than sweet and bittersweet samples, $9 \pm 5$ and $31 \pm 32 \mathrm{mg} \cdot \mathrm{kg}^{-1}$, respectively. This result was expected since these target compounds are responsible for the characteristic hot taste (de Sá Mendes \& Branco de Andrade Gonçalves, 2020). Besides, within a specific flavor type, the capsaicinoid/carotenoid ratios between non-smoked and smoked samples showed similar behavior (Table S1). Thus, they were jointly considered in the subsequent studies. Regarding individual target compounds, among capsaicinoids, DC 
and CAP were found in major concentrations within all hot, sweet, and bittersweet samples, whereas NDCT was not detected in any sample above its MLOD.

The carotenoid content usually did not significantly differ when comparing the different types (hot, sweet, and bittersweet) of samples from the same region (Table S2). Hungarian samples had the highest total content of carotenoids, independently of the flavor type. For instance, the total carotenoid amounts of hot La Vera, Murcia, and the Czech Republic paprika samples were $106 \pm 51,118 \pm 69$, and $75 \pm 24 \mathrm{mg} \cdot \mathrm{kg}^{-1}$, respectively; whereas hot Hungary samples contained $719 \pm 192 \mathrm{mg} \cdot \mathrm{kg}^{-1}$. Besides, in accordance to Giuffrida et. al. (Giuffrida et al., 2013), ß-CAR was found to be the most predominant carotenoid (15-510 $\left.\mathrm{mg} \cdot \mathrm{kg}^{-1}\right)$ in all samples, followed by ß-CRYPT (25-360 $\left.\mathrm{mg} \cdot \mathrm{kg}^{-1}\right)$, and CT (6-270 $\left.\mathrm{mg} \cdot \mathrm{kg}^{-1}\right)$. Intead, VIO and CR occurred at lower concentrations (4.2-42 $\left.\mathrm{mg} \cdot \mathrm{kg}^{-1}\right)$. Moreover, although it seemed that LUT was detected in samples from Hungary, this signal may be due to zeaxanthin (ZEA), which is a lutein isomer that cannot be separated from LUT using a C18 column (Kim, Geon, Park, Pyo, \& Kim, 2016) and whose presence has been reported previously in red paprika (Deli, Molnár, Matus, \& Tóth, 2001; Hassan, Yusof, Yahaya, Rozali, \& Othman, 2019). Because of the structural similarities between ZEA and LUT, which may lead to comparable ionization efficiency, ZEA was quantified using LUT standard. Furthermore, VIO could not be quantified in samples from the Czech Republic and Murcia, since its concentration was below its MLOQ. Therefore, because of the observed differences in the presence of capsaicinoid and carotenoid, they were proposed as chemical descriptors to address paprika authentication based on chemometrics.

\subsection{Multivariate data analysis}

In views of the qualitative and quantitative differences between paprika samples of different geographical origins and types, the concentrations of carotenoids and 
capsaicinoids were proposed as chemical descriptors to address their authentication by

420 multivariate data analysis. PCA was preliminarily applied to check the behavior of paprika and QC samples. Hence, the data matrix of $151 \times 10$ (samples $\times$ variables) dimension, containing the calculated carotenoid and capsaicinoid content for the analyzed paprika and QC samples (15), was studied. The scores plot of PC1 vs. PC2 depicted in Fig. S2A (PC1 and PC2 explained variance of 50.23 and 31.18\%, respectively) showed that QC samples appeared in the middle of the plot, meaning the absence of systematic errors in the data acquisition and validating the chemometric results. Moreover, high Hotelling $\mathrm{T}^{2}$ and $\mathrm{Q}$ residual values were not observed (Fig. S2B), suggesting the absence of outlier samples.

PLS-DA was chosen as the chemometric technique to conduct the classificatory analysis. A first PLS-DA model was built, which included all the paprika samples under study, according to both origins, and type. Thus, a $136 \times 10 \mathrm{X}$-data matrix and a Y-data matrix, assigning samples to nine classes, were used. Fig. 4 shows the corresponding scores plot of LV1 vs. LV2 (two LVs, explaining the 18.29\% Y-variance, were chosen 434 for constructing the PLS-DA model), where remarkable discrimination between types could be seen. In this line, sweet samples were located on the upper side of the plot, whereas the hot ones on the bottom. Variable importance in projection (VIP) values indicated that this separation was mainly because of CAP, NDC, and DC contents. However, bittersweet La Vera samples did not present significant differences with $L a$ Vera sweet ones, so they were considered both as sweet in the following chemometric 440 studies. Regarding the production area, Hungary paprika samples were clearly distinguished in the right part of the plot (displaying positive LV1 scores values) from the other samples, whose classification was not achieved with this PLS-DA model. 
Therefore, considering the complexity of the classification due to the wide range of classes, the design of a classification decision tree formed by smaller PLS-DA models was proposed. The followed path to achieve sample classification is shown in Fig. 5 and consisted of four main steps in the PLS-DA model: firstly, hot vs. sweet; secondly, Hungary vs. others; thirdly, La Vera vs. others; and finally, Murcia vs. the Czech Republic. Calibration model details such as data matrices dimensions, CV approach, LVs for their construction, $\mathrm{X}$ and $\mathrm{Y}$-variance explained, and calibration sensitivity and specificity, are also given in Fig. 5. These PLS-DA calibration models, whose classification scores plots of some of them are depicted in Fig. S3, were built with $70 \%$ of the analyzed paprika samples as the training set $(89 \times 10$, dimension data matrix), while the external validation was carried out with the remaining $30 \%(47 \times 10$, dimension data matrix). Satisfactory results regarding the geographical origin classification of paprika samples by the determination of carotenoid and capsaicinoid were obtained with a rate of $80.9 \%$. When evaluating the results by origins, $87.5,60.0,90.0$, and $100.0 \%$ rates were reached for Hungary, La Vera, Murcia, and the Czech Republic paprika samples, respectively. Most of La Vera misclassified samples were assigned as Murcia samples and backward, which could indicate that specific external conditions related to the country of origin (e.g., climate or farmland) are related to the capsaicinoid and carotenoid profile.

\section{Conclusions}

In this work, the UHPLC-APCI-HRMS capsaicinoid and carotenoid profile have proved to be an adequate chemical descriptor to classify and authenticate paprika samples from different geographical origins (La Vera, Murcia, Hungary, and the Czech Republic) and types (hot, sweet and bittersweet). One of the main advantages of the proposed UHPLC-APCI-HRMS methods is the efficient ionization of both capsaicinoids and 
Besides, a total classification rate of $80.9 \%$ was led by building a classification decision tree based on consecutive PLS-DA models and performing an external validation. The breaking down of this result by origin reached $87.5,60.0,90.0$, and $100.0 \%$ rates for Hungary, La Vera, Murcia, and the Czech Republic samples, respectively. The capsaicinoid content was strongly related to the flavor paprika type, while the carotenoid content could be associated with the country of origin by external conditions since most La Vera misclassified samples were assigned as Murcia samples and backward.

In future estudies, other geographical origin paprika samples could be also tested to further demonstrate the wide applicability of the proposed UHPLC-APCI-HRMS method. Additionally, other carotenoids, capsaicinoids or derivative compounds (e.g., antheraxanthin, cryptocapsin, or capsanthin-3,6-epoxide) could also be included as target compounds to provide UHPLC-APCI-HRMS profiles with richer information. Finally, the use of data fusion strategies combining the capsaicinoid and carotenoid profile with the polyphenolic profile, as well as other supervised classificatory chemometric techniques such as orthogonal projections to latent structures-discriminant analysis (OPLS-DA) or soft independent modeling of class analogy (SIMCA) could also be explored in future works to further improve the classification of paprika samples.

Acknowledgements

Authors acknowledge the financial support from the Spanish Ministry of Science, Innovation and Universities (PGC2018-095013-B-I00), and from the Agency for Management of University and Research Grants, Government of Catalonia (2017SGR310). Ane Arrizabalaga-Larrañaga thanks the Agency for Management of University and 
494 Arimboor, R., Natarajan, R. B., Menon, K. R., Chandrasekhar, L. P., \& Moorkoth, V.

495

496

497

498

499

500

501

502

503

504

505

506

507

508

509

510

511

512

513

514

515

516

517 (2015). Red pepper (Capsicum annuum) carotenoids as a source of natural food colors: analysis and stability—a review. Journal of Food Science and Technology, 52(3), 1258-1271. https://doi.org/10.1007/s13197-014-1260-7

Arrizabalaga-Larrañaga, A., Rodríguez, P., Medina, M., Santos, F. J., \& Moyano, E. (2019). Simultaneous analysis of natural pigments and E-141i in olive oils by liquid chromatography-tandem mass spectrometry. Analytical and Bioanalytical Chemistry, 411(21), 5577-5591. https://doi.org/10.1007/s00216-019-01939-3

Arrizabalaga-Larrañaga, A., Rodríguez, P., Medina, M., Santos, F. J., \& Moyano, E. (2020). Pigment profiles of Spanish extra virgin olive oils by ultra-highperformance liquid chromatography coupled to high-resolution mass spectrometry. Food Additives and Contaminants - Part A Chemistry, Analysis, Control, Exposure and Risk Assessment, 37(7), 1075-1086.

https://doi.org/10.1080/19440049.2020.1753891

Barbero, G. F., Liazid, A., Ferreiro-González, M., Palma, M., \& Barroso, C. G. (2016). Fast separation of capsaicinoids from peppers by reversed phase ultra-performance liquid chromatography: Comparation with traditional high-performance liquid chromatography methods. International Journal of Food Properties, 19(5), 984992. https://doi.org/10.1080/10942912.2015.1050673

Barbosa, S., Saurina, J., Puignou, L., \& Nuñez, O. (2020). Targeted UHPLC-HRMS (Orbitrap) Polyphenolic and Capsaicinoid Profiling for the Chemometric Characterization and Classification of Paprika with Protected Designation of Origin (PDO) Attributes. Molecules, 25, 1-16. https://doi.org/10.3390/molecules25071623 
Barbosa, S., Saurina, J., Puignou, L., \& Núñez, O. (2020). Classification and authentication of paprika by UHPLC-HRMS fingerprinting and multivariate calibration methods (PCA and PLS-DA). Foods, 9(4). https://doi.org/10.3390/foods9040486

Bijttebier, S., Zhani, K., D’Hondt, E., Noten, B., Hermans, N., Apers, S., \& Voorspoels, S. (2014). Generic characterization of apolar metabolites in red chili peppers (Capsicum frutescens L.) by orbitrap mass spectrometry. Journal of Agricultural and Food Chemistry, 62(20), 4812-4831. https://doi.org/10.1021/jf500285g

Breemen, R. B. van, Dong, L., \& Pajkovic, N. D. (2012). Atmospheric Pressure chemical Ionization Tandem Mass Spectrometry of Carotenoids. International Journal of Mass Spectrometry, 312, 163-172. https://doi.org/10.1016/j.jims.2011.07.030

Brunner, M., Katona, R., Stefánka, Z., \& Prohaska, T. (2010). Determination of the geographical origin of processed spice using multielement and isotopic pattern on the example of Szegedi paprika. European Food Research and Technology, 231(4), 623-634. https://doi.org/10.1007/s00217-010-1314-7

Campmajó, G., Núñez, N., \& Núñez, O. (2019). The Role of Liquid ChromatographyMass Spectrometry in Food Integrity and Authenticity. In G. S. Kamble (Ed.), Mass Spectrometry - Future Perceptions and Applications (pp. 3-20). https://doi.org/http://dx.doi.org/10.5772/57353

Cetó, X., Sánchez, C., Serrano, N., Díaz-Cruz, J. M., \& Núñez, O. (2020). Authentication of paprika using HPLC-UV fingerprints. Lwt, 124(December 2019). https://doi.org/10.1016/j.lwt.2020.109153

Cetó, X., Serrano, N., Aragó, M., Gámez, A., Esteban, M., Díaz-Cruz, J. M., \& Núñez, O. (2018). Determination of HPLC-UV fingerprints of spanish paprika (Capsicum 
annuum L.) for its classification by linear discriminant analysis. Sensors (Switzerland), 18(12). https://doi.org/10.3390/s18124479

Daood, H. G., Halasz, G., Palotás, G., Palotás, G., Bodai, Z., \& Helyes, L. (2015). HPLC determination of capsaicinoids with cross-linked C18 column and buffer-

de Sá Mendes, N., \& Branco de Andrade Gonçalves, É. C. (2020). The role of bioactive free eluent. Journal of Chromatographic Science, 53(1), 135-143. https://doi.org/10.1093/chromsci/bmu030 components found in peppers. Trends in Food Science and Technology, 99(February), 229-243. https://doi.org/10.1016/j.tifs.2020.02.032

Deli, J., Molnár, P., Matus, Z., \& Tóth, G. (2001). Carotenoid composition in the fruits of red paprika (Capsicum annuum var. lycopersiciforme rubrum) during ripening; biosynthesis of carotenoids in red paprika. Journal of Agricultural and Food Chemistry, 49(3), 1517-1523. https://doi.org/10.1021/jf000958d

European Commission. eAmbrosia - the EU geographical indications register. (2020). Retrieved May 8, 2020, from https://ec.europa.eu/info/food-farming-fisheries/foodsafety-and-quality/certification/quality-labels/geographical-indications-register/

Food and Agriculture Organization of the United Nations. (2019). Retrieved May 8, 2020, from Food and agriculture data website: http://www.fao.org/faostat/en/\#data/QC/visualize/

Food Fraud Risk Information. (2020). Retrieved May 8, 2020, from Food fraud risk information database. website: https://rello.com/b/aoFO1UEf/food-fraud-riskinformation/

Galvin-King, P., Haughey, S. A., \& Elliott, C. T. (2018). Herb and spice fraud; the drivers, challenges and detection. Food Control, 88, 85-97. https://doi.org/10.1016/j.foodcont.2017.12.031 
568 Giuffrida, D., Dugo, P., Torre, G., Bignardi, C., Cavazza, A., Corradini, C., \& Dugo, G. 569 (2013). Characterization of 12 Capsicum varieties by evaluation of their carotenoid $570 \quad$ profile and pungency determination. Food Chemistry, 140(4), 794-802. https://doi.org/10.1016/j.foodchem.2012.09.060

Hassan, N. M., Yusof, N. A., Yahaya, A. F., Rozali, N. N. M., \& Othman, R. (2019). Carotenoids of capsicum fruits: Pigment profile and health-promoting functional attributes. Antioxidants, 8(10), 1-25. https://doi.org/10.3390/antiox8100469

Hong, E., Lee, S. Y., Jeong, J. Y., Park, J. M., Kim, B. H., Kwon, K., \& Chun, H. S. (2017). Modern analytical methods for the detection of food fraud and adulteration by food category. Journal of the Science of Food and Agriculture, 97(12), 3877-

Kim, J., Geon, C., Park, J., Pyo, Y., \& Kim, S. (2016). Carotenoid profiling from 27 types of paprika ( Capsicum annuum L .) with different colors, shapes , and cultivation methods. FOOD CHEMISTRY, 201, 64-71. https://doi.org/10.1016/j.foodchem.2016.01.041

Massart, D. L., Vandeginste, B. G. M., Buydens, L. M. C., de Jong, S., Lewi, P.J., \& Smeyers-Verbeke, J. (1997). . In Elsevier (Ed.), Handbook of chemometrics and qualimetrics (1st ed.). Amsterdam.

Medina, S., Perestrelo, R., Silva, P., Pereira, J. A. M., \& Câmara, J. S. (2019). Current trends and recent advances on food authenticity technologies and chemometric approaches. Trends in Food Science and Technology, 85(December 2018), 163176. https://doi.org/10.1016/j.tifs.2019.01.017

Mudrić, S., Gašić, U. M., Dramićanin, A. M., Ćirić, I., Milojković-Opsenica, D. M., Popović-Đorđević, J. B., ... Tešić, Ž. L. (2017). The polyphenolics and carbohydrates as indicators of botanical and geographical origin of Serbian 
autochthonous clones of red spice paprika. Food Chemistry, 217, 705-715. https://doi.org/10.1016/j.foodchem.2016.09.038

Nagy, Z., Daood, H., Koncsek, A., Molnár, H., \& Helyes, L. (2017). The simultaneous determination of capsaicinoids, tocopherols, and carotenoids in pungent pepper powder. Journal of Liquid Chromatography and Related Technologies, 40(4), 199-209. https://doi.org/10.1080/10826076.2017.1297722

Ördög, A., Poór, P., Štajner, D., Popović, B., Bátori, Z., \& Tari, I. (2018). Comparison of the mineral content of processed spice samples of sweet and hot paprika from the szeged region*. Journal of Elementology, 23(2), 521-530. https://doi.org/10.5601/jelem.2017.22.4.1497

Palacios-Morillo, A., Jurado, J. M., Alcázar, A., \& Pablos, F. (2016). Differentiation of Spanish paprika from Protected Designation of Origin based on color measurements and pattern recognition. Food Control, 62, 243-249. https://doi.org/10.1016/j.foodcont.2015.10.045

Palacios-Morillo, Ana, Jurado, J. M., Alcázar, Á., \& De Pablos, F. (2014). Geographical characterization of Spanish PDO paprika by multivariate analysis of multielemental content. Talanta, 128, 15-22. https://doi.org/10.1016/j.talanta.2014.04.025

Reilly, C. A., Ehlhardt, W. J., Jackson, D. A., Kulanthaivel, P., Mutlib, A. E., Espina, R. J., ... Yost, G. S. (2003). Metabolism of capsaicin by cytochrome P450 produces novel dehydrogenated metabolites and decreases cytotoxicity to lung and liver cells. Chemical Research in Toxicology, 16(3), 336-349. https://doi.org/10.1021/tx025599q

Schweiggert, U., Carle, R., \& Schieber, A. (2006). Characterization of major and minor capsaicinoids and related compounds in chili pods (Capsicum frutescens L.) by 
high-performance liquid chromatography/atmospheric pressure chemical ionization mass spectrometry. Analytica Chimica Acta, 557(1-2), 236-244. https://doi.org/10.1016/j.aca.2005.10.032

Serrano, N., Cetó, X., Núñez, O., Aragó, M., Gámez, A., Ariño, C., \& Díaz-Cruz, J. M. (2018). Characterization and classification of Spanish paprika (Capsicum annuum L.) by liquid chromatography coupled to electrochemical detection with screenprinted carbon-based nanomaterials electrodes. Talanta, 189(June), 296-301. https://doi.org/10.1016/j.talanta.2018.06.085

Stipcovich, T., Barbero, G. F., Ferreiro-González, M., Palma, M., \& Barroso, C. G. (2018). Fast analysis of capsaicinoids in Naga Jolokia extracts (Capsicum chinense) by high-performance liquid chromatography using fused core columns. Food Chemistry, 239, 217-224. https://doi.org/10.1016/j.foodchem.2017.06.098

Václav Štursa , Pavel Diviš, J. P. (2018). CHARACTERISTICS OF PAPRIKA SAMPLES OF DIFFERENT GEOGRAPHICAL ORIGIN. Journal, Potravinarstvo Slovak Sciences, Food, 12(1), 254-261. https://doi.org/10.5219/902

Wolf, R., Huschka, C., Raith, K., Wohlrab, W., \& Neubert, R. H. H. (1999). Rapid quantification of capsaicin and dihydrocapsaicin in human skin extracts after dermal administration using HPLC-ESI-MS. Journal of Liquid Chromatography and Related Technologies, 22(4), 531-539. https://doi.org/10.1081/JLC100101678 
642 Fig. 1 Chemical structures, acronyms, and chemical formula of the studied capsaicinoids and carotenoids.

644 Fig. 2 HRMS spectrum and AIF (HRMS) spectrum of (A) DC and (B) CT.

645 Fig. 3 UHPLC-APCI-HRMS capsaicinoid and carotenoid profile chromatograms of sweet paprika samples from (A) Murcia, sample MS9, and (B) Hungary, sample HS5.

648 Fig. 4 PLS-DA Scores plot of LV1 vs. LV2, using the UHPLC-HRMS capsaicinoid 649 and carotenoid profiling for the classification of all the paprika samples 650 tested.

651 Fig. 5 Classification decision tree built by HMB for paprika geographical origin authentication by means of PLS-DA models. Dimensions, CV used method, LVs, and sensitivity and specificity of the model are detailed.

654

655 
Table 1. Description of the samples analysed in the paprika classification study.

\begin{tabular}{llllllll}
\hline Country & Region & Abbreviation & \multicolumn{2}{l}{ Number of samples } & PDO & $\begin{array}{l}\text { Production } \\
\text { year }\end{array}$ \\
\cline { 3 - 8 } & & & $\begin{array}{l}\text { Hot } \\
(\mathrm{H})\end{array}$ & $\begin{array}{l}\text { Sweet } \\
(\mathrm{S})\end{array}$ & $\begin{array}{l}\text { Bittersweet } \\
(\mathrm{BS})\end{array}$ & & \\
\hline Spain & La Vera & V & $15^{\mathrm{a}}$ & $15^{\mathrm{a}}$ & $15^{\mathrm{a}}$ & Yes & 2017 \\
& Murcia & $\mathrm{M}$ & 15 & 15 & - & Yes & 2017 \\
Hungary & Kalocsa & H & 18 & $18+$ & - & No & 2018 \\
& & & $+5^{\mathrm{a}}$ & $5^{\mathrm{a}}$ & & & \\
Czzech & - & CR & 5 & $5+5^{\mathrm{a}}$ & - & No & 2017 \\
Republic & & & & & & &
\end{tabular}


Table 2. Retention time, ion assignment and accurate mass error of target compounds obtained from the UHPLC-HRMS and AIF (HRMS) data.

\begin{tabular}{|c|c|c|c|c|c|c|c|}
\hline \multirow[t]{2}{*}{ Compound } & LC & \multicolumn{3}{|c|}{ HRMS } & \multicolumn{3}{|c|}{ MS/HRMS } \\
\hline & $\begin{array}{l}t_{R} \\
(\min )\end{array}$ & $\begin{array}{l}\text { Experimental } m / z \\
\text { (Rel. Ab. \%) }\end{array}$ & Ion Assignment & $\begin{array}{l}\text { Accurate mass } \\
\text { error (ppm) }\end{array}$ & Fragment ion $(\mathrm{m} / \mathrm{z})$ & Ion Assignment & $\begin{array}{l}\text { Accurate mass } \\
\text { error (ppm) }\end{array}$ \\
\hline \multirow[t]{5}{*}{ NDC } & 4.30 & $294.2060(100)$ & {$[\mathrm{M}+\mathrm{H}]^{+}$} & -1.0 & 158.1536 & {$\left[\mathrm{M}+\mathrm{H}-\mathrm{C}_{8} \mathrm{H}_{8} \mathrm{O}_{2}\right]^{+}$} & -1.9 \\
\hline & & 158.1537 (85) & {$\left[\mathrm{M}+\mathrm{H}-\mathrm{C}_{8} \mathrm{H}_{8} \mathrm{O}_{2}\right]^{+}$} & -1.3 & 137.0595 & {$\left[\mathrm{C}_{8} \mathrm{H}_{9} \mathrm{O}_{2}\right]^{+}$} & -1.5 \\
\hline & & 137.0598 (25) & {$\left[\mathrm{C}_{8} \mathrm{H}_{9} \mathrm{O}_{2}\right]^{+}$} & 0.7 & 122.0362 & {$\left[\mathrm{C}_{7} \mathrm{H}_{6} \mathrm{O}_{2}\right]^{+\bullet}$} & 0.0 \\
\hline & & & & & 94.0417 & {$\left[\mathrm{C}_{7} \mathrm{H}_{6} \mathrm{O}_{2}-\mathrm{CO}\right]^{+\bullet}$} & 4.2 \\
\hline & & & & & 66.0465 & {$\left[\mathrm{C}_{7} \mathrm{H}_{6} \mathrm{O}_{2}-\mathrm{C}_{2} \mathrm{O}_{2}\right]^{+\bullet}$} & 1.5 \\
\hline \multirow[t]{4}{*}{ CAP } & 4.33 & 306.2056 (100) & {$[\mathrm{M}+\mathrm{H}]^{+}$} & -2.3 & 137.0594 & {$\left[\mathrm{C}_{8} \mathrm{H}_{9} \mathrm{O}_{2}\right]^{+}$} & -2.2 \\
\hline & & $170.1536(15)$ & {$\left[\mathrm{M}+\mathrm{H}-\mathrm{C}_{8} \mathrm{H}_{8} \mathrm{O}_{2}\right]^{+}$} & 0.0 & 122.0362 & {$\left[\mathrm{C}_{7} \mathrm{H}_{6} \mathrm{O}_{2}\right]^{+\bullet}$} & 0.0 \\
\hline & & 137.0595 (75) & {$\left[\mathrm{C}_{8} \mathrm{H}_{9} \mathrm{O}_{2}\right]^{+}$} & -1.4 & 94.0417 & {$\left[\mathrm{C}_{7} \mathrm{H}_{6} \mathrm{O}_{2}-\mathrm{CO}\right]^{+\bullet}$} & 4.2 \\
\hline & & & & & 66.0465 & {$\left[\mathrm{C}_{7} \mathrm{H}_{6} \mathrm{O}_{2}-\mathrm{C}_{2} \mathrm{O}_{2}\right]^{+\bullet}$} & 3.0 \\
\hline \multirow[t]{5}{*}{ DC } & 4.50 & $308.2214(100)$ & {$[\mathrm{M}+\mathrm{H}]^{+}$} & -1.9 & 172.1692 & {$\left[\mathrm{M}+\mathrm{H}-\mathrm{C}_{8} \mathrm{H}_{8} \mathrm{O}_{2}\right]^{+}$} & -2.3 \\
\hline & & $172.1693(30)$ & {$\left[\mathrm{M}+\mathrm{H}-\mathrm{C}_{8} \mathrm{H}_{8} \mathrm{O}_{2}\right]^{+}$} & -1.7 & 137.0595 & {$\left[\mathrm{C}_{8} \mathrm{H}_{9} \mathrm{O}_{2}\right]^{+}$} & -1.4 \\
\hline & & 137.0596 (35) & {$\left[\mathrm{C}_{8} \mathrm{H}_{9} \mathrm{O}_{2}\right]^{+}$} & -0.7 & 122.0362 & {$\left[\mathrm{C}_{7} \mathrm{H}_{6} \mathrm{O}_{2}\right]^{+\bullet}$} & 0.0 \\
\hline & & & & & 94.0417 & {$\left[\mathrm{C}_{7} \mathrm{H}_{6} \mathrm{O}_{2}-\mathrm{CO}\right]^{+\bullet}$} & 4.2 \\
\hline & & & & & 66.0465 & {$\left[\mathrm{C}_{7} \mathrm{H}_{6} \mathrm{O}_{2}-\mathrm{C}_{2} \mathrm{O}_{2}\right]^{+\bullet}$} & 1.5 \\
\hline \multirow[t]{4}{*}{ NDCT } & 5.32 & $137.0596(100)$ & {$\left[\mathrm{C}_{8} \mathrm{H}_{9} \mathrm{O}_{2}\right]^{+}$} & -0.7 & 137.0595 & {$\left[\mathrm{C}_{8} \mathrm{H}_{9} \mathrm{O}_{2}\right]^{+}$} & -1.5 \\
\hline & & & & & 122.0362 & {$\left[\mathrm{C}_{7} \mathrm{H}_{6} \mathrm{O}_{2}\right]^{+\bullet}$} & 0.8 \\
\hline & & & & & 94.0417 & {$\left[\mathrm{C}_{7} \mathrm{H}_{6} \mathrm{O}_{2}-\mathrm{CO}\right]^{+\bullet}$} & 4.2 \\
\hline & & & & & 66.0465 & {$\left[\mathrm{C}_{7} \mathrm{H}_{6} \mathrm{O}_{2}-\mathrm{C}_{2} \mathrm{O}_{2}\right]^{+\bullet}$} & 1.5 \\
\hline \multirow[t]{2}{*}{ CR } & 7.03 & $601.4241(30)$ & {$[\mathrm{M}+\mathrm{H}]^{+}$} & -1.7 & 221.1531 & {$\left[\mathrm{C}_{14} \mathrm{H}_{21} \mathrm{O}_{2}\right]^{+}$} & -2.3 \\
\hline & & $583.4137(100)$ & {$\left[\mathrm{M}+\mathrm{H}-\mathrm{H}_{2} \mathrm{O}\right]^{+}$} & -1.4 & 109.1013 & {$\left[\mathrm{C}_{8} \mathrm{H}_{13}\right]^{+}$} & 1.8 \\
\hline \multirow[t]{3}{*}{ VIO } & 7.45 & $601.424(100)$ & {$[\mathrm{M}+\mathrm{H}]^{+}$} & -1.8 & 583.4132 & {$\left[\mathrm{M}+\mathrm{H}-\mathrm{H}_{2} \mathrm{O}\right]^{+}$} & -2.2 \\
\hline & & 583.4137 (45) & {$\left[\mathrm{M}+\mathrm{H}-\mathrm{H}_{2} \mathrm{O}\right]^{+}$} & -1.4 & 221.153 & {$\left[\mathrm{C}_{14} \mathrm{H}_{21} \mathrm{O}_{2}\right]^{+}$} & -2.7 \\
\hline & & & & & 165.0907 & {$\left[\mathrm{C}_{10} \mathrm{H}_{13} \mathrm{O}_{2}\right]^{+}$} & -1.9 \\
\hline
\end{tabular}




\begin{tabular}{|c|c|c|c|c|c|c|c|}
\hline \multirow{3}{*}{ CT } & \multirow{3}{*}{7.28} & \multirow{3}{*}{$\begin{array}{l}585.4291(100) \\
567.4186(45)\end{array}$} & \multirow{3}{*}{$\begin{array}{l}{[\mathrm{M}+\mathrm{H}]^{+}} \\
{\left[\mathrm{M}+\mathrm{H}-\mathrm{H}_{2} \mathrm{O}\right]^{+}}\end{array}$} & \multirow{3}{*}{-1.9} & \multirow{2}{*}{$\begin{array}{l}119.0853 \\
567.4183\end{array}$} & \multirow{2}{*}{$\begin{array}{l}{\left[\mathrm{C}_{9} \mathrm{H}_{11}\right]^{+}} \\
{\left[\mathrm{M}+\mathrm{H}-\mathrm{H}_{2} \mathrm{O}\right]^{+}}\end{array}$} & \multirow{2}{*}{$\begin{array}{l}-1.9 \\
-2.3\end{array}$} \\
\hline & & & & & & & \\
\hline & & & & & 119.0856 & {$\left[\mathrm{C}_{9} \mathrm{H}_{11}\right]^{+}$} & 0.6 \\
\hline & & & & & 109.1013 & {$\left[\mathrm{C}_{8} \mathrm{H}_{13}\right]^{+}$} & 1.8 \\
\hline \multirow[t]{3}{*}{ LUT } & 8.23 & 569.4349 (20) & {$[\mathrm{M}+\mathrm{H}]^{+}$} & -0.7 & 145.101 & {$\left[\mathrm{C}_{11} \mathrm{H}_{13}\right]^{+}$} & -1.2 \\
\hline & & $551.4239(100)$ & {$\left[\mathrm{M}+\mathrm{H}-\mathrm{H}_{2} \mathrm{O}\right]^{+}$} & -1.4 & 119.0856 & {$\left[\mathrm{C}_{9} \mathrm{H}_{11}\right]^{+}$} & 0.6 \\
\hline & & & & & 105.0701 & {$\left[\mathrm{C}_{8} \mathrm{H}_{9}\right]^{+}$} & 2.2 \\
\hline \multirow[t]{4}{*}{$\beta-\mathrm{CRYPT}$} & 11.60 & $553.4394(100)$ & {$[\mathrm{M}+\mathrm{H}]^{+}$} & -1.8 & 535.4294 & {$\left[\mathrm{M}+\mathrm{H}-\mathrm{H}_{2} \mathrm{O}\right]^{+}$} & -0.7 \\
\hline & & $535.4291(25)$ & {$\left[\mathrm{M}+\mathrm{H}-\mathrm{H}_{2} \mathrm{O}\right]^{+}$} & -1.3 & 145.101 & {$\left[\mathrm{C}_{11} \mathrm{H}_{13}\right]^{+}$} & -1.2 \\
\hline & & & & & 119.0856 & {$\left[\mathrm{C}_{9} \mathrm{H}_{11}\right]^{+}$} & 0.6 \\
\hline & & & & & 105.0701 & {$\left[\mathrm{C}_{8} \mathrm{H}_{9}\right]^{+}$} & 2.2 \\
\hline \multirow[t]{3}{*}{$\beta-\mathrm{CAR}$} & 12.30 & $537.4445(100)$ & {$[\mathrm{M}+\mathrm{H}]^{+}$} & -1.9 & 177.1634 & {$\left[\mathrm{C}_{13} \mathrm{H}_{21}\right]^{+}$} & -1.7 \\
\hline & & & & & 119.0856 & {$\left[\mathrm{C}_{9} \mathrm{H}_{11}\right]^{+}$} & 0.8 \\
\hline & & & & & 105.0700 & {$\left[\mathrm{C}_{8} \mathrm{H}_{9}\right]^{+}$} & 1.2 \\
\hline
\end{tabular}


Figure 1

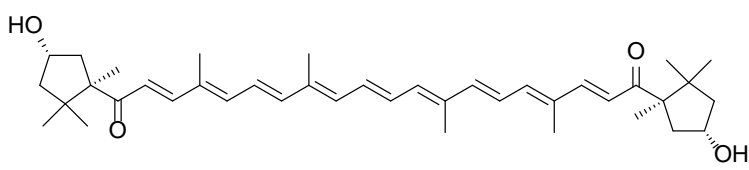

Capsorubin (CR) $\mathrm{C}_{40} \mathrm{H}_{56} \mathrm{O}_{4}$

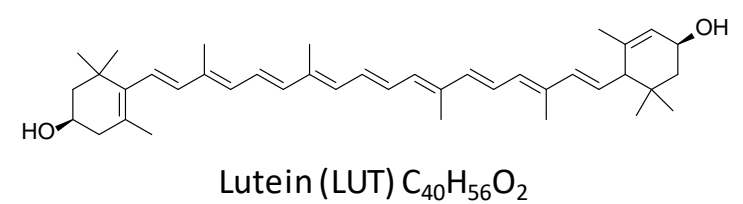

(loc)

Violaxanthin (VIO) $\mathrm{C}_{40} \mathrm{H}_{56} \mathrm{O}_{4}$<smiles>COc1cc(CNC(=O)CCCC/C=C/C(C)C)ccc1O</smiles>

Capsaicin (CAP) $\mathrm{C}_{18} \mathrm{H}_{27} \mathrm{NO}_{3}$<smiles>COc1cc(CNC(=O)CCCCCC(C)C)ccc1O</smiles>

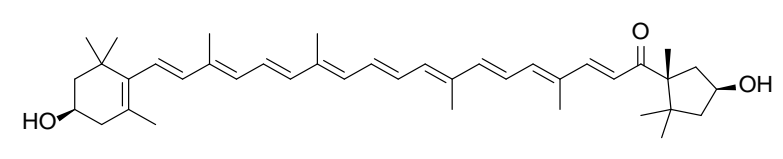

Capsanthin (CT) $\mathrm{C}_{40} \mathrm{H}_{56} \mathrm{O}_{3}$
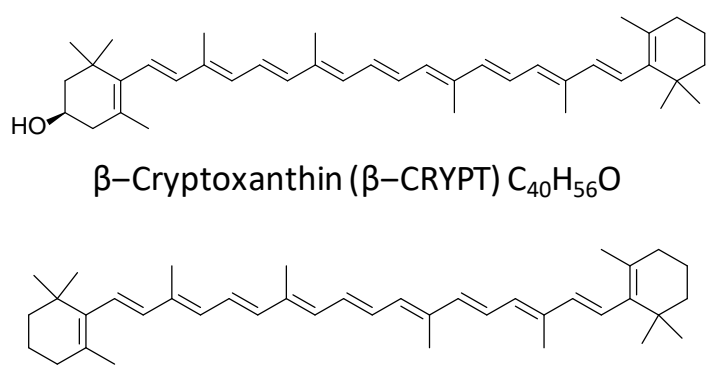

$\beta$-Carotene $(\beta-C A R) \mathrm{C}_{18} \mathrm{H}_{27} \mathrm{NO}_{3}$<smiles>COC1=CC(CNC(=O)CCCC/C=C/C(C)C)CC=C1O</smiles>

Dihydrocapsaicin (DC) $\mathrm{C}_{18} \mathrm{H}_{29} \mathrm{NO}_{3}$<smiles>COc1cc(COC(=O)CCCCCC(C)C)ccc1O</smiles>

Nordihydro 
Figure 2

A)

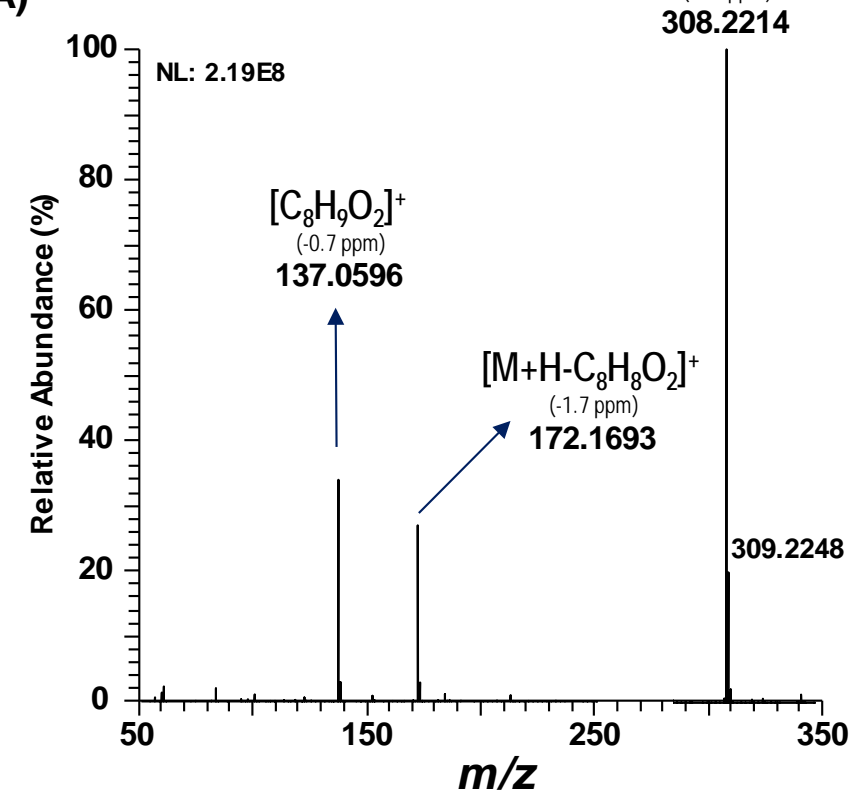

B)

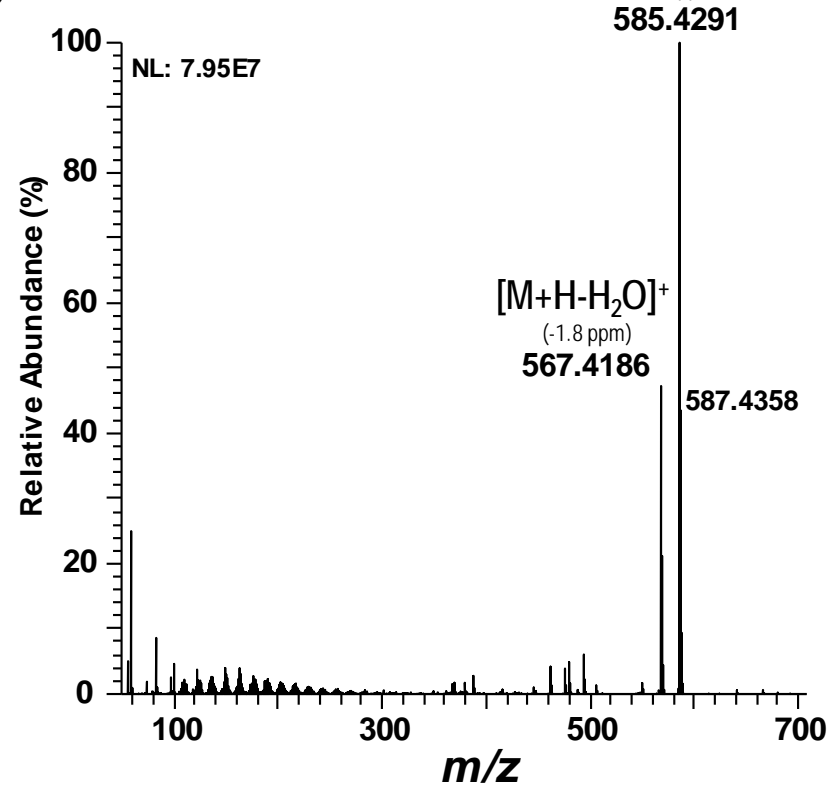

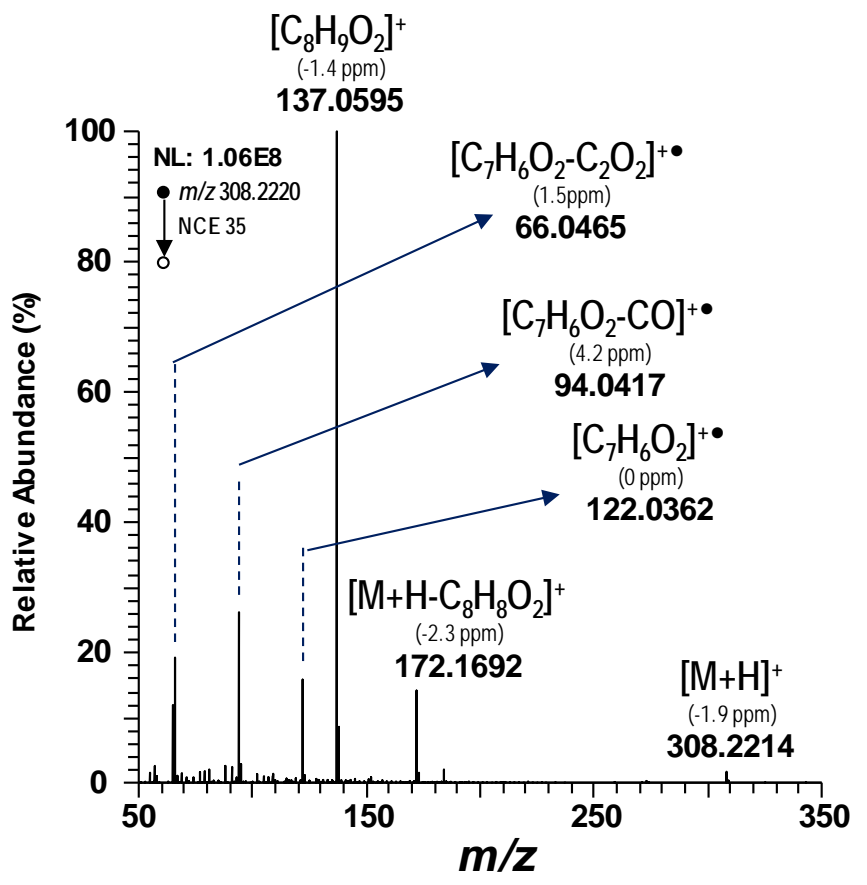

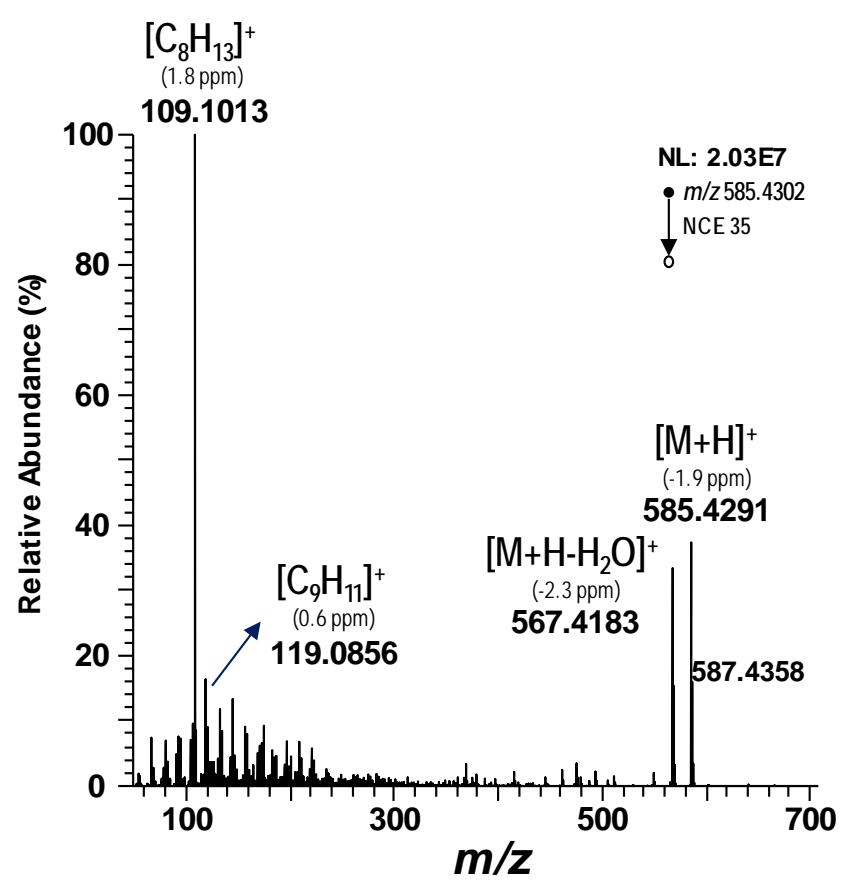




\section{Figure 3}
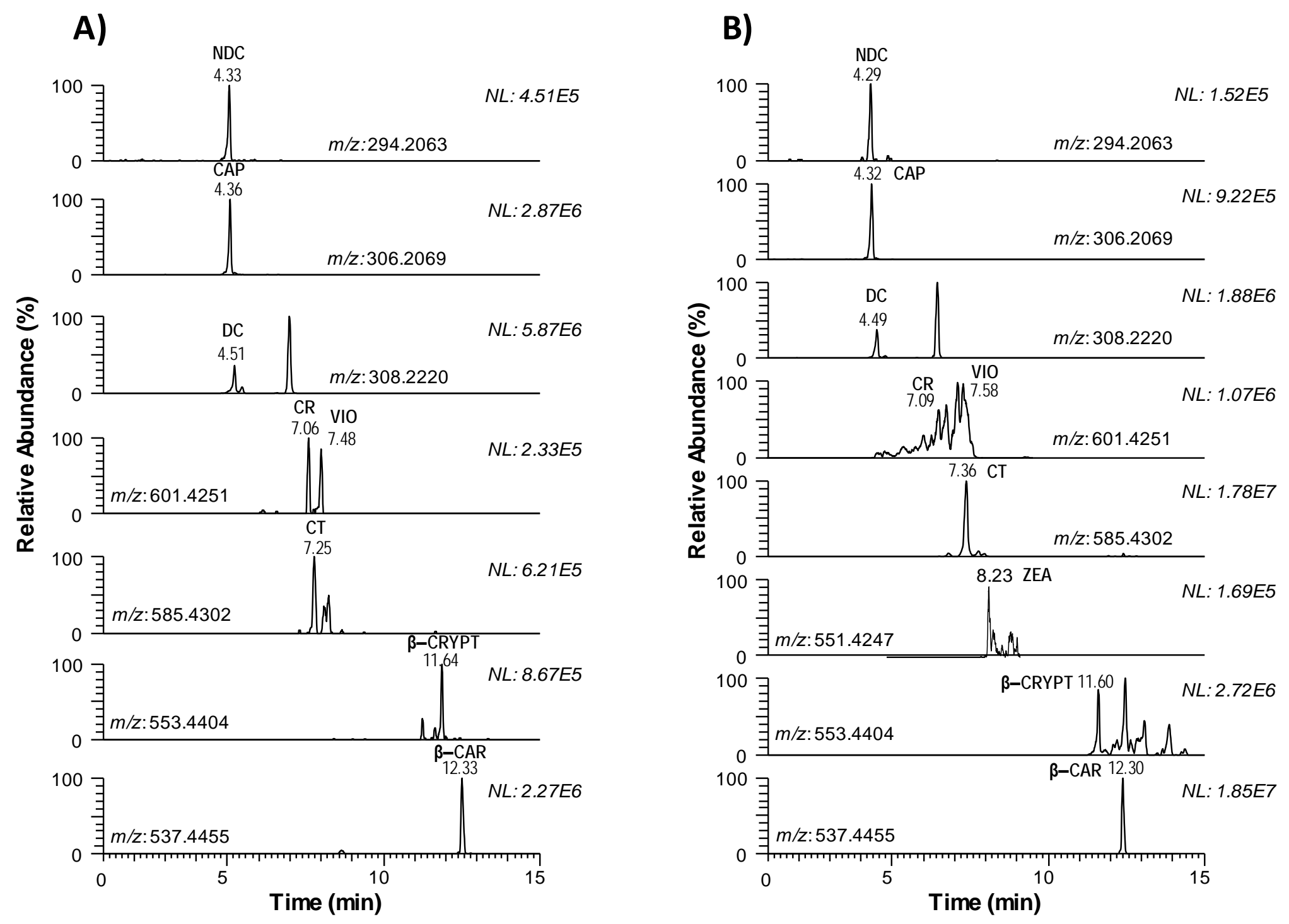
Figure 4

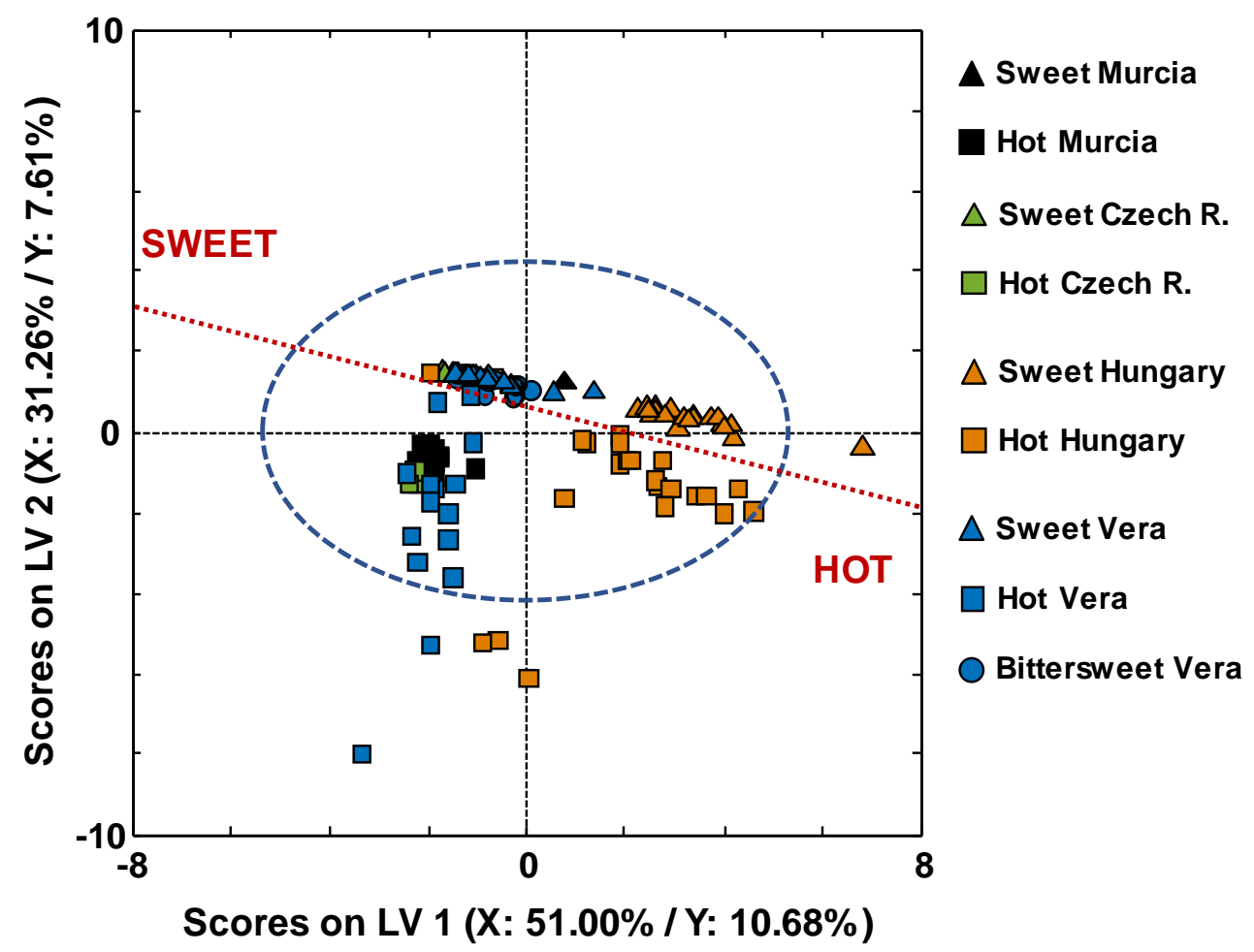




\section{Figure 5}

\begin{tabular}{|c|c|c|c|c|c|}
\hline Hot vs. Sweet & HOI & Hot Hungary vs. others & HOT HUNGARY & & \\
\hline$X: 89 \times 10, Y: 89 \times 1$ & & - $X: 38 \times 10, Y: 38 \times 1$ & & & \\
\hline Venetian blinds & & - Venetian blinds & Hot La Vera vs. others & HOT LA VERA & \\
\hline $1 \mathrm{LV}(\mathrm{X}: 35.59 \%$ / Y: 50.21\%) & & - 2 LVs (X: 85.05\% / Y: 78.96\%) & - $X: 23 \times 10, Y: 23 \times 1$ & & \\
\hline CAL sensitivity: 95\% & & - CAL sensitivity: $93 \%$ & - Venetian blinds & Hot Murcia vs. hot Czech Rep. & HOT MURCIA \\
\hline \multirow[t]{15}{*}{ CAL specificity: $100 \%$} & & - CAL specificity: $100 \%$ & - 1 LV (X: 44.76\% / Y: 53.85\%) & $X: 13 \times 10, Y: 13 \times 1$ & \\
\hline & & & - CAL sensitivity: $90 \%$ & Leave-one-out & HOT CZECH REPUBLIC \\
\hline & SWEET & & - CAL specificity: $100 \%$ & - $1 \operatorname{LV}(X: 44.35 \% / Y: 82.02 \%)$ & \\
\hline & & & & - CAL sensitivity: $100 \%$ & \\
\hline & & & & CAL specificity: $100 \%$ & \\
\hline & & Sweet Hungary vs. others & SWEET HUNGARY & & \\
\hline & & - X: $51 \times 10, Y: 51 \times 1$ & & & \\
\hline & & - Venetian blinds & Sweet La Vera vs. others & SWEET LA VERA & \\
\hline & & - 1 LV (X: 51.29\% / Y: 84.92\%) & - $X: 36 \times 10, Y: 36 \times 1$ & & \\
\hline & & - CAL sensitivity: $100 \%$ & - Venetian blinds & Sweet Murcia vs. sweet Czech Rep. & SWEET MURCIA \\
\hline & & CAL specificity: $97 \%$ & - 2 LVs (X: 55.07\% / Y: 42.35\%) & - $X: 16 \times 10, Y: 16 \times 1$ & \\
\hline & & & - CAL sensitivity: $75 \%$ & - Leave-one-out & SWEET CZECH REPUBLIC \\
\hline & & & - CAL specificity: $94 \%$ & - 3 LVs (X: 68.03\% / Y: 58.61\%) & \\
\hline & & & & - CAL sensitivity: $90 \%$ & \\
\hline & & & & - CAL specificity: $83 \%$ & \\
\hline
\end{tabular}




\section{Determination of capsaicinoids and carotenoids for the characterization} and geographical origin authentication of paprika by UHPLC-APCIHRMS

Ane Arrizabalaga-Larrañaga ${ }^{\#(1)}$, Guillem Campmajó ${ }^{\#(1.2)}$, Javier Saurina ${ }^{(1,2)}$, Oscar Núñez ${ }^{(1,2,3)}$, Francisco Javier Santos ${ }^{(1)}$, Encarnación Moyano ${ }^{(1) *}$

(1) Department of Chemical Engineering and Analytical Chemistry, University of Barcelona, Barcelona, Spain

(2) Research Institute in Food Nutrition and Food Safety, University of Barcelona, Santa Coloma de Gramenet, Spain

(3) Serra Húnter Program, Generalitat de Catalunya, Barcelona, Spain

* Corresponding author: E. Moyano

\section{Table of Contents}

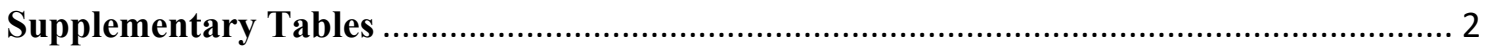

Table S1. Concentrations $\left(\mathrm{mg} \cdot \mathrm{kg}^{-1}\right)$ of capsaicinoids and carotenoids determined in paprika samples.

Table S2. Total capsaicinoid content ( $\Sigma$ CAPS), total carotenoid content ( $\Sigma$ CAR), and their respective sum $(\Sigma$ CAPS $+\Sigma$ CAR), expressed as mean \pm standard deviation, obtained for the analyzed paprika samples according to their geographical origin and flavor variety.

Supplementary Figures

Figure S1: Capsaicinoid (blue) and carotenoid (orange) distribution of Paprika from different origins and varieties.

Figure S2: (A) PCA Scores plot of PC1 vs. PC2, showing a correct behavior of QC samples. (B) Hotelling T2 vs. Q residual values plot for the detection of outlier samples.

Figure S3: Classification plot depicting Samples vs. Y Predicted 1 Scores plot for the PLS-DA calibration models of (A) hot vs. sweet, (B) hot Hungary vs. others, (C) hot La Vera vs. others, and (D) hot Murcia vs. Czech Republic. 10 


\section{Supplementary Tables}

Table S1. Concentrations $\left(\mathrm{mg} \cdot \mathrm{kg}^{-1}\right)$ of capsaicinoids and carotenoids determined in paprika samples.

\begin{tabular}{|c|c|c|c|c|c|c|c|c|c|c|}
\hline Sample & $\mathrm{NDC}$ & CAP & $\mathrm{DC}$ & NDCT & $\mathrm{CR}$ & $\mathrm{VIO}$ & $\mathrm{CT}$ & ZEA & $\beta-\mathrm{CRYPT}$ & $\beta-\mathrm{CAR}$ \\
\hline${ }^{a}$ VH1 & 17 & 180 & 242 & nd & 9.1 & 6.0 & 12 & nd & 64 & 70 \\
\hline${ }^{\mathrm{a}} \mathrm{VH} 2$ & 31 & 288 & 373 & nd & $<\mathrm{LOQ}$ & $<$ LOQ & 9.5 & nd & $<\mathrm{LOQ}$ & 15 \\
\hline${ }^{\mathrm{a}} \mathrm{VH} 3$ & 62 & 507 & 692 & nd & 11 & 7.5 & 16 & $<\mathrm{LOQ}$ & 68 & 59 \\
\hline${ }^{\mathrm{a}} \mathrm{VH} 4$ & 52 & 409 & 594 & nd & $<\mathrm{LOQ}$ & $<\mathrm{LOQ}$ & 16 & $<\mathrm{LOQ}$ & 17 & 19 \\
\hline${ }^{\mathrm{a}} \mathrm{VH} 5$ & 33 & 341 & 375 & nd & 7.4 & $<\mathrm{LOQ}$ & 6.4 & nd & 46 & 28 \\
\hline${ }^{\mathrm{a}} \mathrm{VH6}$ & 45 & 478 & 554 & nd & 10 & 7.0 & 12 & nd & 55 & 55 \\
\hline${ }^{\mathrm{a}} \mathrm{VH} 7$ & 137 & 1020 & 1133 & nd & 9.0 & 5.4 & $<$ LOQ & nd & $<\mathrm{LOQ}$ & 15 \\
\hline${ }^{\mathrm{a}} \mathrm{VH} 8$ & 31 & 381 & 478 & nd & 7.1 & 6.0 & 7.7 & nd & $<\mathrm{LOQ}$ & 33 \\
\hline${ }^{\mathrm{a}} \mathrm{VH} 9$ & 11 & 78 & 104 & nd & $<\mathrm{LOQ}$ & $<\mathrm{LOQ}$ & $<\mathrm{LOQ}$ & nd & 28 & 37 \\
\hline${ }^{\mathrm{a}} \mathrm{VH} 10$ & 57 & 510 & 644 & nd & 9.5 & 5.8 & $<\mathrm{LOQ}$ & nd & $<\mathrm{LOQ}$ & 18 \\
\hline${ }^{\mathrm{a}} \mathrm{VH} 11$ & 34 & 279 & 373 & nd & 7.9 & $<\mathrm{LOQ}$ & 14 & $<\mathrm{LOQ}$ & 63 & 95 \\
\hline${ }^{\mathrm{a}} \mathrm{VH} 12$ & 26 & 349 & 643 & nd & 8.7 & 8.5 & 13 & nd & 25 & 47 \\
\hline${ }^{\mathrm{a}} \mathrm{VH} 13$ & 6.8 & 42.4 & 66.5 & nd & 7.2 & $<\mathrm{LOQ}$ & 8.3 & nd & 54 & 57 \\
\hline${ }^{\mathrm{a}} \mathrm{VH} 14$ & 29.2 & 361.6 & 368.4 & nd & 6.0 & $<$ LOQ & 7.5 & nd & 49 & 38 \\
\hline${ }^{\mathrm{a}} \mathrm{VH} 15$ & 85.4 & 691.8 & 919.4 & nd & 14 & 6.6 & 15 & nd & 60 & 57 \\
\hline${ }^{\mathrm{a}} \mathrm{VS} 1$ & 0.5 & 3.1 & 5.5 & nd & 8.6 & $<\mathrm{LOQ}$ & 9.8 & nd & 54 & 77 \\
\hline${ }^{\mathrm{a}} \mathrm{VS} 2$ & 0.8 & 4.9 & 7.6 & nd & 13 & 6.9 & $<\mathrm{LOQ}$ & nd & 79 & 119 \\
\hline${ }^{\mathrm{a}} \mathrm{VS} 3$ & 0.5 & 1.1 & 3.1 & nd & 13 & 13 & 220 & nd & 126 & 119 \\
\hline${ }^{\mathrm{a}} \mathrm{VS} 4$ & 1.4 & 6.3 & 12 & nd & 7.5 & $<\mathrm{LOQ}$ & 11 & nd & 69 & 82 \\
\hline${ }^{\mathrm{a}}$ VS5 & 0.3 & 1.4 & 2.6 & nd & 7.4 & 6.0 & 112 & nd & $<\mathrm{LOQ}$ & 35 \\
\hline${ }^{\mathrm{a}} \mathrm{VS} 6$ & 1.6 & 7.6 & 12 & nd & 11 & 6.3 & 35 & $<\mathrm{LOQ}$ & 82 & 57 \\
\hline${ }^{\mathrm{a}} \mathrm{VS} 7$ & 0.2 & 1.2 & 3.1 & nd & 7.4 & $<\mathrm{LOQ}$ & 13 & nd & 43 & 83 \\
\hline${ }^{\mathrm{a}} \mathrm{VS} 8$ & $<\mathrm{LOQ}$ & 0.8 & 1.7 & nd & 7.3 & 5.6 & 19 & 31 & 39 & 25 \\
\hline${ }^{\mathrm{a}} \mathrm{VS} 9$ & 1.5 & 7.5 & 13 & nd & $<\mathrm{LOQ}$ & $<\mathrm{LOQ}$ & $<\mathrm{LOQ}$ & nd & 73 & 52 \\
\hline
\end{tabular}

${ }^{\mathrm{a}}$ smoked paprika sample; nd: not detected ( $<$ MLOD) 
Table S1. (Cont) Concentrations $\left(\mathrm{mg} \cdot \mathrm{kg}^{-1}\right)$ of capsaicinoids and carotenoids determined in paprika samples.

\begin{tabular}{|c|c|c|c|c|c|c|c|c|c|c|}
\hline Sample & NDC & CAP & $\mathrm{DC}$ & NDCT & $\mathrm{CR}$ & $\mathrm{VIO}$ & $\mathrm{CT}$ & ZEA & $\beta-$ CRYPT & $\beta-\mathrm{CAR}$ \\
\hline${ }^{\mathrm{a}} \mathrm{VS} 10$ & 0.7 & 2.7 & 5.7 & nd & 8.3 & 6.3 & 16 & nd & 62 & 55 \\
\hline avS11 & 1.1 & 5.2 & 8.0 & nd & 16 & 11 & 37 & $<\mathrm{LOQ}$ & 121 & 81 \\
\hline aVS12 & 0.6 & 3.0 & 4.6 & nd & $<\mathrm{LOQ}$ & $<\mathrm{LOQ}$ & 11 & nd & 73 & 37 \\
\hline${ }^{\mathrm{a}} \mathrm{VS} 13$ & 0.4 & 1.4 & 3.3 & nd & 6.5 & $<$ LOQ & 7.4 & nd & $<\mathrm{LOQ}$ & 50 \\
\hline aVS14 & $<\mathrm{LOQ}$ & 0.8 & 1.7 & nd & 12 & 8.3 & 13 & nd & 64 & 70 \\
\hline a VS15 & 0.4 & 1.0 & 2.5 & nd & 7.4 & $<\mathrm{LOQ}$ & 12 & nd & 25 & 49 \\
\hline${ }^{\mathrm{a}} \mathrm{VBS}$ & 4.6 & 36 & 47 & nd & 13.0 & 7.3 & 18 & $<\mathrm{LOQ}$ & 78 & 79 \\
\hline avBS & 1.3 & 11 & 15 & nd & 12.5 & $<\mathrm{LOQ}$ & 15 & nd & 49 & 56 \\
\hline${ }^{a}$ VBS & 2.1 & 14 & 21 & nd & 6.1 & $<\mathrm{LOQ}$ & 5.5 & nd & 24 & 34 \\
\hline${ }^{\mathrm{a}} \mathrm{VBS}$ & 6.7 & 39 & 58 & nd & 9.1 & 6.9 & 24 & $<\mathrm{LOQ}$ & 48 & 22 \\
\hline${ }^{a}$ VBS & 4.4 & 26 & 41 & nd & 15 & 7.8 & 15 & nd & 69 & 93 \\
\hline${ }^{\mathrm{a}} \mathrm{VBS}$ & 0.8 & 4.8 & 6.3 & nd & 5.3 & $<\mathrm{LOQ}$ & 19 & nd & 64 & 48 \\
\hline${ }^{a}$ VBS & 0.6 & 3.7 & 6.2 & nd & 17 & 9.3 & 25 & nd & 52 & 40 \\
\hline${ }^{\mathrm{a}} \mathrm{VBS}$ & 0.4 & 1.6 & 2.6 & nd & 9.0 & 5.6 & 16 & nd & $<\mathrm{LOQ}$ & 55 \\
\hline${ }^{\mathrm{a}} \mathrm{VBS}$ & 1.3 & 4.9 & 7.8 & nd & $<\mathrm{LOQ}$ & $<\mathrm{LOQ}$ & 6.7 & nd & 35 & 85 \\
\hline${ }^{\mathrm{a}} \mathrm{VBS}$ & 0.4 & 1.3 & 3.1 & nd & 8.2 & $<\mathrm{LOQ}$ & 12 & nd & 54 & 101 \\
\hline${ }^{\mathrm{a}} \mathrm{VBS}$ & 1.7 & 18 & 19 & nd & 17 & 8.9 & 19 & nd & 85 & 116 \\
\hline${ }^{\mathrm{a}} \mathrm{VBS}$ & 0.6 & 4.2 & 5.7 & nd & 11 & 5.7 & 16 & nd & 69 & 63 \\
\hline${ }^{\mathrm{a}} \mathrm{VBS}$ & 0.6 & 2.0 & 3.9 & nd & 14 & 7.2 & 14 & nd & 79 & 117 \\
\hline${ }^{\mathrm{a}} \mathrm{VBS}$ & 1.9 & 9.8 & 17 & nd & 13 & 7.8 & 16 & nd & 78 & 105 \\
\hline${ }^{a}$ VBS & 0.8 & 4.9 & 7.3 & nd & 9.4 & 5.5 & 11 & nd & 55 & 79 \\
\hline MH1 & 25 & 272 & 257 & nd & $<\mathrm{LOQ}$ & $<\mathrm{LOQ}$ & $<\mathrm{LOQ}$ & nd & 17 & 68 \\
\hline MH2 & 27 & 292 & 269 & nd & $<\mathrm{LOQ}$ & $<\mathrm{LOQ}$ & $<\mathrm{LOQ}$ & nd & 40 & 59 \\
\hline MH3 & 25 & 251 & 271 & nd & $<\mathrm{LOQ}$ & $<\mathrm{LOQ}$ & 5.3 & nd & 25 & 61 \\
\hline MH4 & 24 & 240 & 254 & nd & $<\mathrm{LOQ}$ & $<\mathrm{LOQ}$ & $<\mathrm{LOQ}$ & nd & 21 & 65 \\
\hline MH5 & 20 & 238 & 244 & nd & $<\mathrm{LOQ}$ & $<\mathrm{LOQ}$ & $<\mathrm{LOQ}$ & nd & $<\mathrm{LOQ}$ & 42 \\
\hline MH6 & 22 & 270 & 278 & nd & $<\mathrm{LOQ}$ & $<\mathrm{LOQ}$ & $<\mathrm{LOQ}$ & nd & 20 & 57 \\
\hline
\end{tabular}

${ }^{\mathrm{a}}$ smoked paprika sample; nd: not detected $(<\mathrm{MLOD})$ 
$\underline{\text { Table S1. (Cont) Concentrations }\left(\mathrm{mg} \cdot \mathrm{kg}^{-1}\right) \text { of capsaicinoids and carotenoids determined in paprika samples. }}$

\begin{tabular}{|c|c|c|c|c|c|c|c|c|c|c|}
\hline Sample & NDC & CAP & DC & NDCT & $\mathrm{CR}$ & VIO & $\mathrm{CT}$ & ZEA & $\beta-$ CRYPT & $\beta-\mathrm{CAR}$ \\
\hline MH7 & 22 & 235 & 240 & nd & $<\mathrm{LOQ}$ & $<\mathrm{LOQ}$ & $<\mathrm{LOQ}$ & nd & 41 & 56 \\
\hline MH8 & 28 & 303 & 300 & nd & $<\mathrm{LOQ}$ & $<\mathrm{LOQ}$ & 261 & nd & 27 & 62 \\
\hline MH9 & 25 & 257 & 252 & nd & $<\mathrm{LOQ}$ & $<\mathrm{LOQ}$ & $<\mathrm{LOQ}$ & nd & 53 & 73 \\
\hline MH10 & 29 & 317 & 317 & nd & $<\mathrm{LOQ}$ & $<\mathrm{LOQ}$ & 6.1 & $<\mathrm{LOQ}$ & 33 & 64 \\
\hline MH11 & 22 & 234 & 214 & nd & $<\mathrm{LOQ}$ & $<\mathrm{LOQ}$ & $<\mathrm{LOQ}$ & nd & 25 & 52 \\
\hline MH12 & 24 & 302 & 266 & nd & $<\mathrm{LOQ}$ & $<\mathrm{LOQ}$ & $<\mathrm{LOQ}$ & nd & $<\mathrm{LOQ}$ & 49 \\
\hline MH13 & 24 & 258 & 247 & nd & $<\mathrm{LOQ}$ & $<$ LOQ & $<\mathrm{LOQ}$ & nd & 44 & 64 \\
\hline MH14 & 25 & 255 & 271 & nd & $<\mathrm{LOQ}$ & $<$ LOQ & $<\mathrm{LOQ}$ & nd & 52 & 61 \\
\hline MH15 & 24 & 234 & 232 & nd & $<\mathrm{LOQ}$ & $<\mathrm{LOQ}$ & $<\mathrm{LOQ}$ & nd & 48 & 32 \\
\hline MS1 & 0.8 & 3.8 & 7.5 & nd & $<\mathrm{LOQ}$ & $<\mathrm{LOQ}$ & $<\mathrm{LOQ}$ & nd & $<\mathrm{LOQ}$ & 18 \\
\hline MS2 & 0.7 & 3.0 & 5.6 & nd & 5.6 & $<\mathrm{LOQ}$ & $<\mathrm{LOQ}$ & nd & $<\mathrm{LOQ}$ & 64 \\
\hline MS3 & 0.7 & 3.3 & 6.6 & nd & $<\mathrm{LOQ}$ & $<\mathrm{LOQ}$ & 5.5 & nd & 42 & 60 \\
\hline MS4 & 0.8 & 3.4 & 5.7 & nd & 6.3 & $<$ LOQ & 5.7 & nd & 47 & 60 \\
\hline MS5 & 0.8 & 3.3 & 5.7 & nd & 6.5 & $<\mathrm{LOQ}$ & 7.7 & nd & 50 & 62 \\
\hline MS6 & 0.8 & 3.3 & 6.5 & nd & 5.3 & $<\mathrm{LOQ}$ & 6.3 & nd & 26 & 69 \\
\hline MS7 & 0.8 & 4.0 & 7.5 & nd & $<\mathrm{LOQ}$ & $<\mathrm{LOQ}$ & 73 & nd & 32 & 71 \\
\hline MS8 & 0.6 & 3.0 & 5.2 & nd & $<\mathrm{LOQ}$ & $<\mathrm{LOQ}$ & 7.1 & nd & 46 & 48 \\
\hline MS9 & 1.1 & 4.0 & 8.1 & nd & 5.3 & $<\mathrm{LOQ}$ & 384 & nd & 124 & 73 \\
\hline MS10 & 0.8 & 3.1 & 5.9 & nd & 5.6 & $<\mathrm{LOQ}$ & $<\mathrm{LOQ}$ & nd & 27 & 72 \\
\hline MS11 & 0.8 & 3.0 & 5.9 & nd & 5.9 & $<\mathrm{LOQ}$ & $<\mathrm{LOQ}$ & nd & 61 & 80 \\
\hline MS12 & 0.7 & 3.6 & 6.0 & nd & 7.4 & $<\mathrm{LOQ}$ & 9.7 & nd & 50 & 68 \\
\hline MS13 & 0.6 & 3.2 & 5.2 & nd & 5.9 & $<\mathrm{LOQ}$ & 6.2 & nd & 53 & 63 \\
\hline MS14 & 0.6 & 3.1 & 6.0 & nd & 5.7 & $<\mathrm{LOQ}$ & 7.4 & nd & 62 & 80 \\
\hline MS15 & 0.8 & 3.8 & 7.0 & nd & $<\mathrm{LOQ}$ & $<\mathrm{LOQ}$ & $<\mathrm{LOQ}$ & nd & 47 & 75 \\
\hline CRH1 & 40 & 280 & 364 & nd & $<\mathrm{LOQ}$ & $<\mathrm{LOQ}$ & $<\mathrm{LOQ}$ & nd & $<\mathrm{LOQ}$ & 49 \\
\hline CRH2 & 41 & 244 & 331 & nd & $<\mathrm{LOQ}$ & $<\mathrm{LOQ}$ & $<\mathrm{LOQ}$ & nd & $<\mathrm{LOQ}$ & 44 \\
\hline CRH3 & 43 & 238 & 367 & nd & $<\mathrm{LOQ}$ & $<\mathrm{LOQ}$ & $<\mathrm{LOQ}$ & nd & 21 & 83 \\
\hline
\end{tabular}

${ }^{\mathrm{a}}$ smoked paprika sample; nd: not detected $(<\mathrm{MLOD})$ 
Table S1. (Cont) Concentrations $\left(\mathrm{mg} \cdot \mathrm{kg}^{-1}\right)$ of capsaicinoids and carotenoids determined in paprika samples.

\begin{tabular}{|c|c|c|c|c|c|c|c|c|c|c|}
\hline Sample & NDC & CAP & $\mathrm{DC}$ & NDCT & $\mathrm{CR}$ & VIO & $\mathrm{CT}$ & ZEA & $\beta-\mathrm{CRYPT}$ & $\beta-\mathrm{CAR}$ \\
\hline CRH4 & 36 & 259 & 323 & nd & $<$ LOQ & $<\mathrm{LOQ}$ & $<\mathrm{LOQ}$ & nd & $<\mathrm{LOQ}$ & 45 \\
\hline CRH5 & 48 & 262 & 338 & nd & $<\mathrm{LOQ}$ & $<\mathrm{LOQ}$ & $<\mathrm{LOQ}$ & nd & $<\mathrm{LOQ}$ & 28 \\
\hline CRS1 & 1.0 & 3.6 & 6.6 & nd & $<\mathrm{LOQ}$ & $<\mathrm{LOQ}$ & 5.7 & nd & $<\mathrm{LOQ}$ & 50 \\
\hline CRS2 & 0.9 & 3.6 & 6.6 & nd & $<\mathrm{LOQ}$ & $<\mathrm{LOQ}$ & 5.7 & nd & $<\mathrm{LOQ}$ & 46 \\
\hline CRS3 & 1.0 & 4.0 & 8.7 & nd & $<\mathrm{LOQ}$ & $<\mathrm{LOQ}$ & 4.9 & nd & 26 & 47 \\
\hline CRS4 & 0.8 & 3.3 & 6.0 & nd & $<\mathrm{LOQ}$ & $<\mathrm{LOQ}$ & 4.8 & nd & 24 & 41 \\
\hline CRS5 & 1.1 & 4.2 & 9.0 & nd & $<\mathrm{LOQ}$ & $<$ LOQ & 6.7 & nd & $<$ LOQ & 44 \\
\hline${ }^{\mathrm{a}} \mathrm{CRS} 1$ & 1.0 & 3.1 & 6.9 & nd & $<\mathrm{LOQ}$ & $<$ LOQ & $<\mathrm{LOQ}$ & nd & 30 & 116 \\
\hline${ }^{\mathrm{a}} \mathrm{CRS} 2$ & 1.0 & 3.2 & 5.9 & nd & $<\mathrm{LOQ}$ & $<\mathrm{LOQ}$ & 31.7 & nd & 81 & 86 \\
\hline${ }^{\mathrm{a}} \mathrm{CRS} 3$ & 1.0 & 3.1 & 8.7 & nd & $<\mathrm{LOQ}$ & $<\mathrm{LOQ}$ & $<\mathrm{LOQ}$ & nd & 31 & 78 \\
\hline${ }^{\mathrm{a}} \mathrm{CRS} 4$ & 0.8 & 3.1 & 6.6 & nd & $<\mathrm{LOQ}$ & $<\mathrm{LOQ}$ & 5.7 & nd & 43 & 88 \\
\hline${ }^{\mathrm{a}} \mathrm{CRS} 5$ & 1.0 & 3.1 & 7.8 & nd & $<\mathrm{LOQ}$ & $<\mathrm{LOQ}$ & $<\mathrm{LOQ}$ & nd & 24 & 123 \\
\hline HH1 & 21 & 151 & 166 & nd & 17 & 9.3 & 109 & 155 & 177 & 212 \\
\hline HH2 & 19 & 138 & 144 & nd & 18 & 9.1 & 103 & 155 & 188 & 230 \\
\hline HH3 & 19 & 134 & 154 & nd & 16 & 9.0 & 104 & 150 & 194 & 283 \\
\hline HH4 & 19 & 59 & 164 & nd & 24 & 10 & 123 & 187 & 123 & 353 \\
\hline HH5 & 27 & 93 & 204 & nd & 29 & 12 & 63 & 343 & 104 & 97 \\
\hline HH6 & 24 & 80 & 179 & nd & 22 & 16 & 5.3 & 284 & 321 & 388 \\
\hline HH7 & 90 & 616 & 805 & nd & 7.8 & 6.6 & 34 & 47 & 160 & 255 \\
\hline HH8 & 91 & 684 & 986 & nd & 8.5 & 10 & 10 & 97 & 189 & 293 \\
\hline HH9 & 85 & 624 & 884 & nd & 10 & 5.6 & 34 & $<\mathrm{LOQ}$ & 115 & 263 \\
\hline HH10 & 17 & 61 & 142 & nd & 21 & 12 & 236 & 240 & 207 & 260 \\
\hline HH11 & 17 & 68 & 153 & nd & 24 & 9.1 & $<\mathrm{LOQ}$ & 89 & 104 & 237 \\
\hline HH12 & 14 & 47 & 125 & nd & 21 & 10 & 71 & 83 & 167 & 282 \\
\hline HH13 & 27 & 98 & 258 & nd & 24 & 15 & 135 & 143 & 140 & 269 \\
\hline HH14 & 31 & 114 & 267 & nd & 24 & 12 & 127 & 158 & 195 & 313 \\
\hline HH15 & 35 & 114 & 293 & nd & 27 & 19 & 45 & 242 & 221 & 362 \\
\hline
\end{tabular}

${ }^{\mathrm{a}}$ smoked paprika sample; nd: not detected $(<\mathrm{MLOD})$ 
Table S1. (Cont) Concentrations $\left(\mathrm{mg} \cdot \mathrm{kg}^{-1}\right)$ of capsaicinoids and carotenoids determined in paprika samples.

\begin{tabular}{|c|c|c|c|c|c|c|c|c|c|c|}
\hline Sample & NDC & CAP & $\mathrm{DC}$ & NDCT & $\mathrm{CR}$ & VIO & $\mathrm{CT}$ & ZEA & $\beta-$ CRYPT & $\beta-\mathrm{CAR}$ \\
\hline HH16 & 16 & 74 & 133 & nd & 17 & 6.6 & 91 & 99 & 226 & 277 \\
\hline HH17 & 15 & 64 & 133 & nd & 13 & 9.1 & 66 & 61 & 152 & 195 \\
\hline HH18 & 17 & 72 & 141 & nd & 19 & 9.5 & $<\mathrm{LOQ}$ & 70 & 154 & 213 \\
\hline HS1 & 0.3 & 1.6 & 3.2 & nd & 26 & 8.6 & 121 & 70 & 202 & 317 \\
\hline $\mathrm{HS} 2$ & 0.4 & 1.2 & 3.0 & nd & 27 & 5.6 & 113 & 105 & 172 & 334 \\
\hline HS3 & 0.5 & 1.7 & 3.5 & nd & 25 & 17 & $<$ LOQ & 312 & 131 & 151 \\
\hline HS4 & 0.2 & 1.1 & 2.1 & nd & 30 & 11 & 112 & 82 & 188 & 446 \\
\hline HS5 & 0.3 & 1.1 & 2.2 & nd & 4.2 & 26 & 39 & 83 & 219 & 500 \\
\hline HS6 & 0.2 & 1.1 & 2.4 & nd & 36 & 12 & 163 & 77 & 168 & 424 \\
\hline HS7 & 0.5 & 1.4 & 3.1 & nd & 23 & 5.3 & 269 & 124 & 181 & 295 \\
\hline HS8 & 0.4 & 1.2 & 2.6 & nd & 25 & 5.2 & 238 & 112 & 148 & 290 \\
\hline HS9 & 0.5 & 1.4 & 2.8 & nd & 31 & 13 & 180 & 186 & 211 & 290 \\
\hline HS 10 & 1.3 & 4.3 & 7.9 & nd & 11 & 13 & 41 & 339 & 237 & 504 \\
\hline HS 11 & 1.2 & 4.1 & 7.6 & nd & 14 & 14 & 48 & 51 & 201 & 486 \\
\hline HS 12 & 1.3 & 4.2 & 7.2 & nd & 11 & 10 & 41 & 94 & 191 & 467 \\
\hline HS 13 & 0.4 & 1.7 & 3.2 & nd & 27 & 8.6 & $<\mathrm{LOQ}$ & 161 & 232 & 218 \\
\hline HS14 & 0.4 & 1.2 & 2.4 & nd & 24 & 15 & 160 & 78 & 300 & 354 \\
\hline HS 15 & 0.4 & 1.7 & 3.6 & nd & 42 & 22 & 213 & 190 & 359 & 496 \\
\hline HS 16 & 0.4 & 1.4 & 2.6 & nd & 22 & 11 & 122 & 148 & 177 & 229 \\
\hline HS 17 & 0.5 & 1.6 & 3.9 & nd & 27 & 13 & 6.7 & 110 & 209 & 303 \\
\hline HS 18 & 0.3 & 1.3 & 2.7 & nd & 22 & 13 & 101 & 64 & 182 & 286 \\
\hline${ }^{\mathrm{a}} \mathrm{HH} 1$ & 32 & 111 & 329 & nd & 33 & 22 & 143 & 140 & 233 & 432 \\
\hline${ }^{\mathrm{a}} \mathrm{HH} 2$ & 33 & 107 & 298 & nd & 24 & 18 & 131 & 104 & 215 & 385 \\
\hline${ }^{\mathrm{a}} \mathrm{HH} 3$ & 30 & 104 & 279 & nd & 27 & 16 & 130 & 169 & 206 & 365 \\
\hline${ }^{\mathrm{a}} \mathrm{HH} 4$ & 40 & 142 & 376 & nd & 15 & 13 & 21 & 124 & 123 & 117 \\
\hline${ }^{\mathrm{a}} \mathrm{HH} 5$ & 38 & 130 & 358 & nd & 28 & 10 & 101 & 108 & 146 & 509 \\
\hline
\end{tabular}

${ }^{\mathrm{a}}$ smoked paprika sample; nd: not detected (<MLOD) 
Table S1. (Cont) Concentrations $\left(\mathrm{mg} \cdot \mathrm{kg}^{-1}\right)$ of capsaicinoids and carotenoids determined in paprika samples.

\begin{tabular}{lllllllllll}
\hline Sample & NDC & CAP & DC & NDCT & CR & VIO & CT & ZEA & $\beta-$ CRYPT & $\beta-$ CAR \\
\hline${ }^{\text {a} H S 1 ~}$ & 1.0 & 3.7 & 9.5 & nd & 26 & 18 & 118 & 101 & 155 & 310 \\
${ }^{\text {a} H S 2 ~}$ & 1.4 & 4.2 & 11 & nd & 28 & 16 & 129 & 110 & 249 & 447 \\
${ }^{a}$ HS3 & 1.4 & 4.2 & 9.7 & nd & 23 & 15 & 129 & 165 & 261 & 382 \\
${ }^{\text {a} H S 4 ~}$ & 1.5 & 4.6 & 10 & nd & 14 & 8.6 & 74 & 117 & 252 & 342 \\
a HS5 & 1.3 & 3.9 & 10 & nd & 29 & 13 & 6.3 & 95 & 233 & 435 \\
\hline
\end{tabular}

${ }^{\mathrm{a}}$ smoked paprika sample; nd: not detected $(<\mathrm{MLOD})$ 
Table S2. Total capsaicinoid content $(\Sigma$ CAPS), total carotenoid content $(\Sigma$ CAR), and their respective sum $(\Sigma$ CAPS $+\Sigma$ CAR), expressed as mean \pm standard deviation, obtained for the analyzed paprika samples according to their geographical origin and flavor variety.

\begin{tabular}{|c|c|c|c|c|c|c|c|c|c|}
\hline & \multicolumn{3}{|c|}{ Hot } & \multicolumn{3}{|c|}{ Sweet } & \multicolumn{3}{|c|}{ Bittersweet } \\
\hline & $\Sigma$ CAPS & $\Sigma \mathrm{CAR}$ & $\Sigma$ CAPS + CAR & $\Sigma$ CAPS & $\Sigma \mathrm{CAR}$ & $\Sigma$ CAPS + CAR & $\Sigma$ CAPS & $\Sigma \mathrm{CAR}$ & $\Sigma$ CAPS + CAR \\
\hline La Vera & $942 \pm 554$ & $106 \pm 50$ & $1048 \pm 547$ & $9 \pm 6$ & $185 \pm 99$ & $194 \pm 100$ & $31 \pm 31$ & $165 \pm 49$ & $196 \pm 61$ \\
\hline Murcia & $549 \pm 53$ & $118 \pm 69$ & $667 \pm 107$ & $10 \pm 1$ & $154 \pm 125$ & $164 \pm 125$ & & & \\
\hline Czech Republic & $642 \pm 27$ & $75 \pm 24$ & $717 \pm 38$ & $12 \pm 1$ & $117 \pm 47$ & $128 \pm 46$ & & & \\
\hline Hungary & $504 \pm 455$ & $719 \pm 192$ & $1224 \pm 432$ & $8 \pm 4$ & $844 \pm 160$ & $851 \pm 161$ & & & \\
\hline
\end{tabular}




\section{Supplementary Figures}
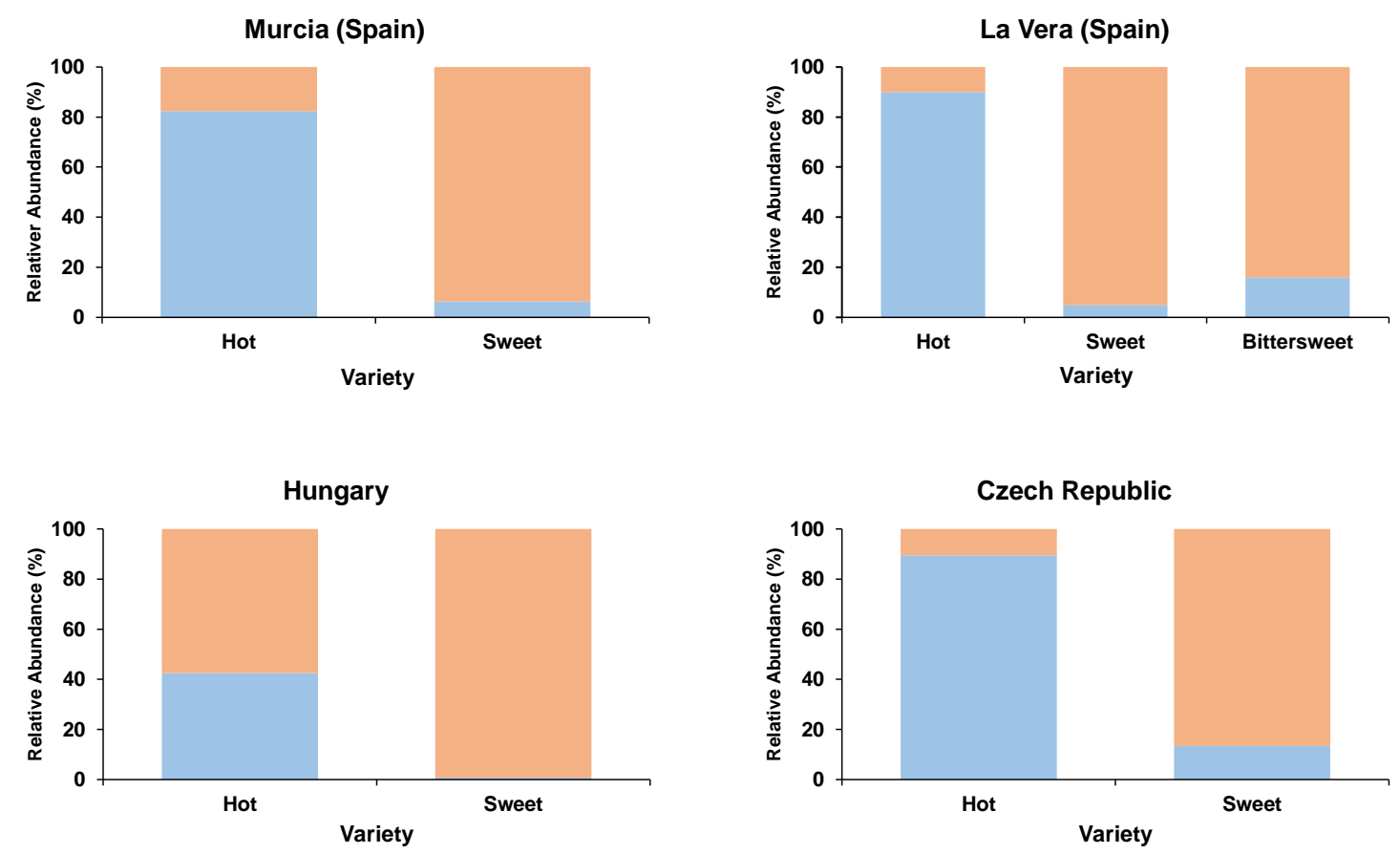

Figure S1: Capsaicinoid (blue) and carotenoid (orange) distribution of Paprika from different origins and varieties.

A)

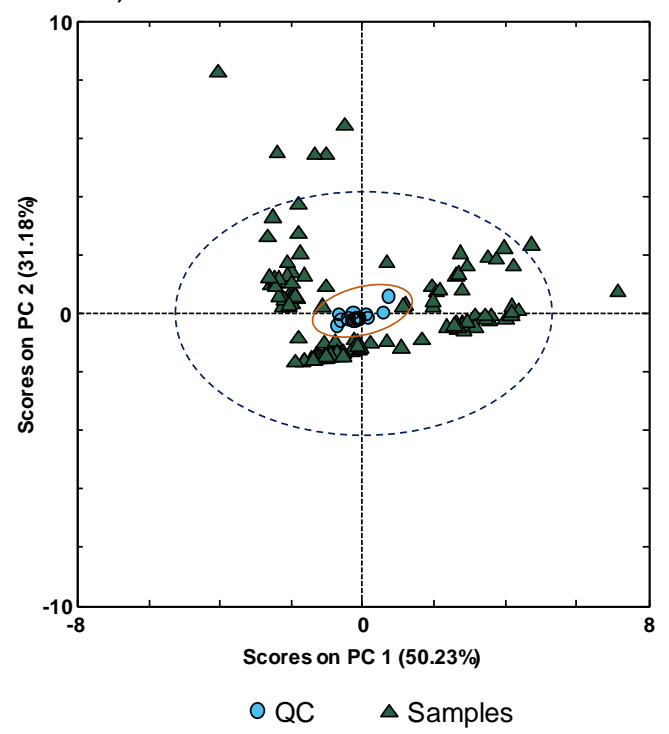

B)

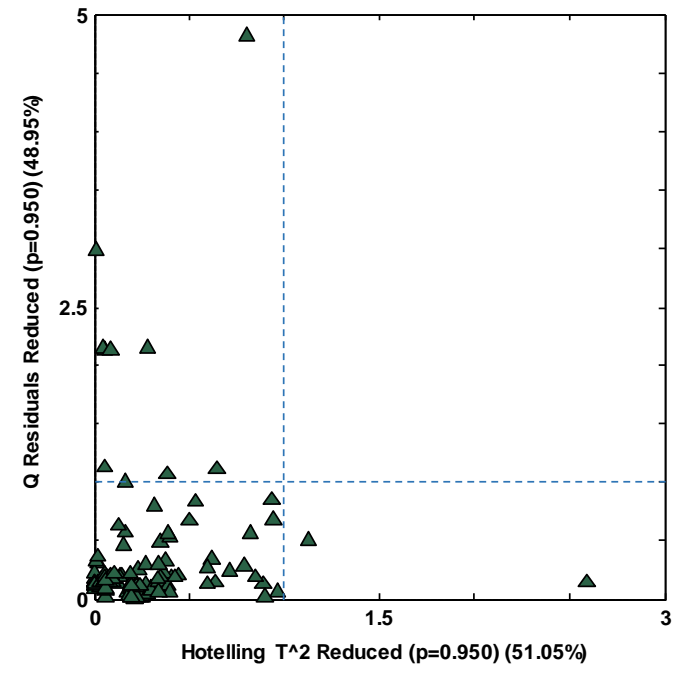

Figure S2: (A) PCA Scores plot of PC1 vs. PC2, showing a correct behavior of QC samples. (B) Hotelling T2 vs. Q residual values plot for the detection of outlier samples. 
A)

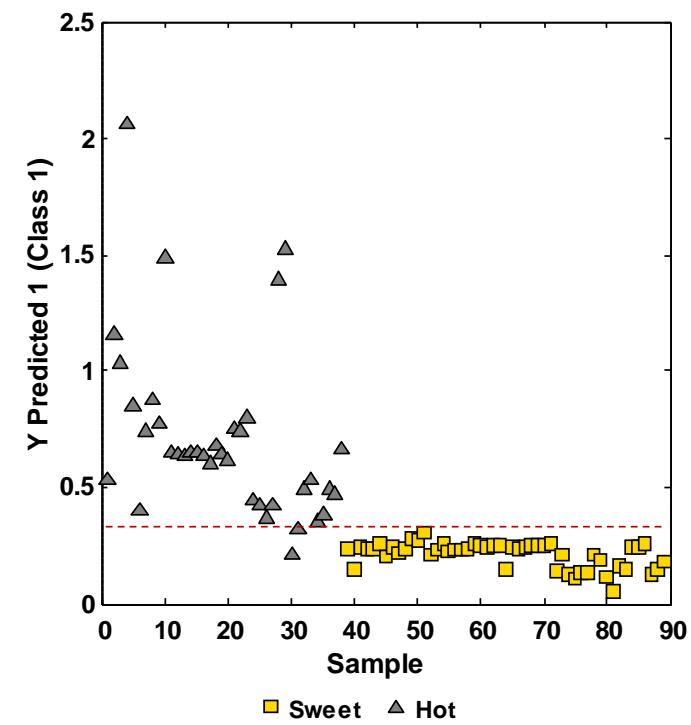

C)

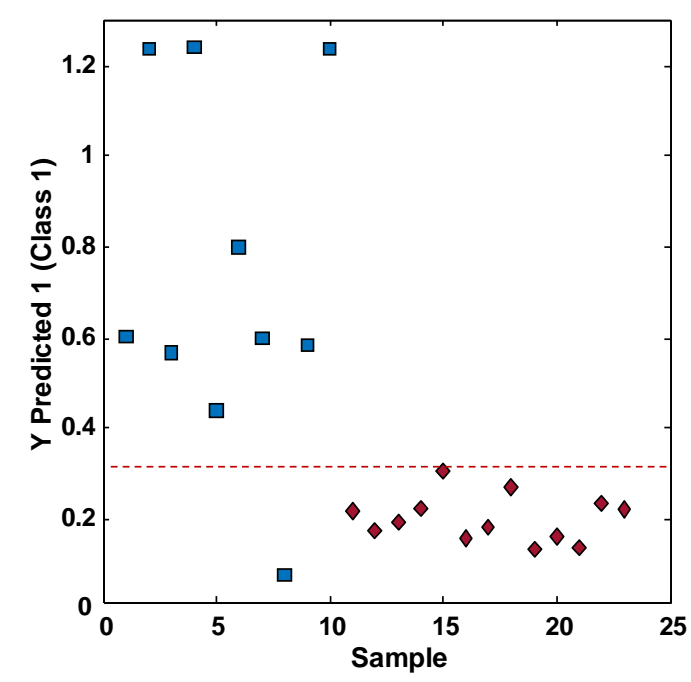

$\square$ Hot La Vera $\diamond$ Others
B)

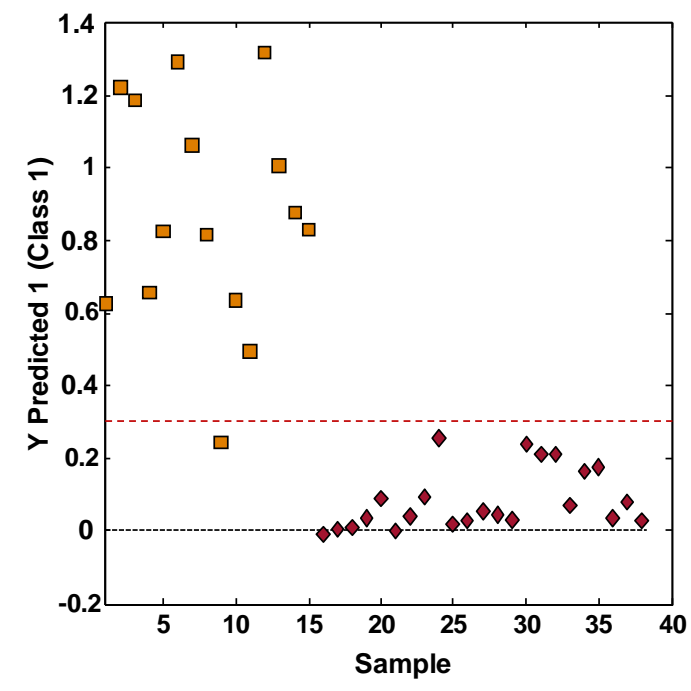

$\square$ Hot Hungary $\diamond$ Others

D)

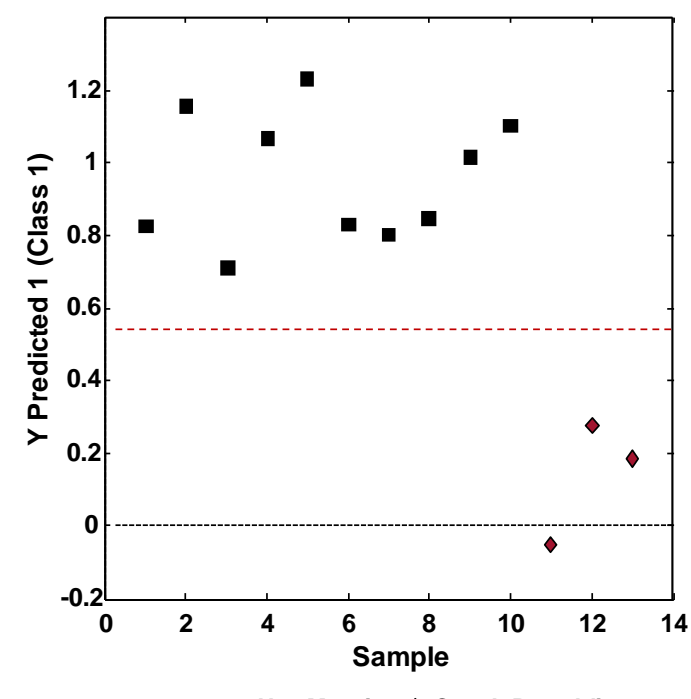

- Hot Murcia $\diamond$ Czech Republic

Figure S3: Classification plot depicting Samples vs. Y Predicted 1 Scores plot for the PLS-DA calibration models of (A) hot vs. sweet, (B) hot Hungary vs. others, (C) hot La Vera vs. others, and (D) hot Murcia vs. Czech Republic. 